Research Article

\title{
Laboratory Performance Evaluation of HMA Modified with Various Types and Contents of Polymer
}

\author{
Cheolmin Baek ${ }^{1}$ and Sangyum Lee $\mathbb{B}^{2}$ \\ ${ }^{1}$ Department of Infrastructure Safety Research, Korea Institute of Civil Engineering and Building Technology, \\ 283 Goyangdae-Ro Ilsanseo-Gu, Goyang-Si, Gyeonggi-Do 10223, Republic of Korea \\ ${ }^{2}$ Department of Construction Information Engineering, Induk University, 12 Choansan-Ro, Nowon-Gu, Seoul 100-110, \\ Republic of Korea \\ Correspondence should be addressed to Sangyum Lee; yummy0220@induk.ac.kr
}

Received 31 March 2018; Accepted 30 July 2018; Published 25 October 2018

Academic Editor: Yinshan Tang

Copyright (c) 2018 Cheolmin Baek and Sangyum Lee. This is an open access article distributed under the Creative Commons Attribution License, which permits unrestricted use, distribution, and reproduction in any medium, provided the original work is properly cited.

\begin{abstract}
Since asphalt binder modifiers for the performance improvement have both good and bad effects on the performance of asphalt pavements, it is important to consider all performance parameters of asphalt pavements for the development of modifiers. This paper evaluates the viscoelastic and plastic properties of four types of asphalt mixtures (three modified mixtures and one unmodified mixture) by laboratory tests, and then, the test results are employed to investigate the effects of modifiers. Test methods adopted in this study are the dynamic modulus test for linear viscoelastic model classified as nondefective test and tension test for constant crosshead rate test and cyclic load test and the triaxial compression test for plastic deformation classified as defective test. The performance for the fatigue failure at the real site's pavement was evaluated by using the VECD-FEP++. The performance of rutting for each mixture was evaluated by using the viscoplastic model from tension test and triaxial compression test proposed by NCHRP 1-37 A MEPDG (AASHTO2004) and the rutting model. The findings from this study support general understanding of the effects of asphalt binder modifier on the fatigue cracking and rutting performance. When considering the performances of rutting and fatigue failure, $\mathrm{K} 2$ mixture is the best SBS-modified material. The modified agent for K1 mixture has low performance than $\mathrm{K} 2$ mixture, and $\mathrm{K} 4$ mixture is good when the rutting is terribly occurred. But it needs serious caution to the failure.
\end{abstract}

\section{Introduction}

Recently, various modifiers are used to improve the performance of asphalt pavements. However, some modifiers have both good and bad effects on the performance of asphalt pavements. For example, modifiers, which are applied to improve the elastic modulus, could increase the rutting performance, whereas they may decrease the cracking performance due to their brittle characteristic. Thus, it is important to consider all performance parameters of asphalt pavements for the development of modifiers. Also, in order to maximize the effects of modifiers, it is necessary to perform researches that can select the advantages of other modifiers properly by comparing chemical and physical components of modifiers and characteristics of modified mixtures. For these researches, the best way is to perform field tests in test sections, but it is not practically easy to do the field test because of construction variables, construction cost, time issue, and so on. Also, the researches based on the laboratory tests are not sufficient to evaluate the effects of modifiers for a wide range of conditions, such as temperatures, loading, and traffic. In order to evaluate the performance of asphalt pavements effectively, many models have been developed and applied. Viscoelastoplastic continuum damage (VEPCD) is one of the practical models, and its main advantage is to model several mechanisms, which play a vital role in the performance of asphalt pavements, separately, so that the VEPCD model can be employed for 
more accurate evaluation of the performance. VEPCD material model can accurately capture various critical phenomena in asphalt mixture, such as microcrack-induced damage, which is critical in fatigue modeling; strain ratetemperature interdependence; and viscoplastic flow, which is critical in high-temperature modeling.

VEPCD is known as a reliable model to predict cracking and rutting on asphalt pavements by the analysis of cracking development, material properties, and viscoplastic on asphalt mixtures. Underwood [1] reported successful performance ranking results on three types of asphalt mixtures including normal HMA by the analysis of model prediction and accelerated loading facility.

\section{Objectives}

The objective of this study was to develop the VEPCD model of four types of mixtures (three modified mixtures and one control mixture) by laboratory tests, and then, the test results are employed to evaluate the effects of modifiers.

\section{Laboratory Test Method}

3.1. Materials and Specimen Fabrication. The four types of asphalt mixtures composed of four types of asphalt binders with aggregates were utilized in this study. The four asphalt binders fall into one unmodified binder and three modified binders with different types and/or contents of SBS modifier. The granite aggregates were utilized and consisted of \#78 aggregate of $36 \%$, dry screening of $25 \%$, wet screening of $38 \%$, and baghouse fine of $1 \%$. Combined gradation for the mixture is shown in Figure 1.

It is one of the most used gradations for paving asphalt pavement of surface layer which means gradation of S9.5C mixture. It can be classified as normal maximum size of aggregate of $9.5 \mathrm{~mm}$ based on Superpave design standards.

To determine the grade for asphalt binders, the general tests for asphalt binders were conducted in accordance with Superpave design standards and are shown in Table 1. The general binder is PG 70-22 and SBS-improved asphalt binder is classified as PG 76-22 according to the results of Table 1. To easily distinguish the four types of mixtures, the names for mixtures are called by KS (asphalt mixture using general binder), K1 (asphalt mixture using KTR-101 binder), K2 (asphalt mixture using KTR-201 binder), and K4 (asphalt mixture using KTR-401H binder) in this paper.

The Superpave mix design was conducted to determine the optimal asphalt content for asphalt mixtures. We have decided that the mix design for a KS mixture can be applied to other mixture designs because the quantity of the tested asphalt binder is limited and our objective is to compare the performances of them with each other. Also, the optimal asphalt content is similar for other mixtures having generally same aggregates and granularity after studying some existing research regarding other types of SBS-improved asphalt mixture. As a result of the mix design for KS mixture, the optimal asphalt content was selected to $5 \%$ at a condition for void ratio of $4 \%$. It has some satisfaction standards for Superpave, which are Void Filled with Asphalt and Voids in

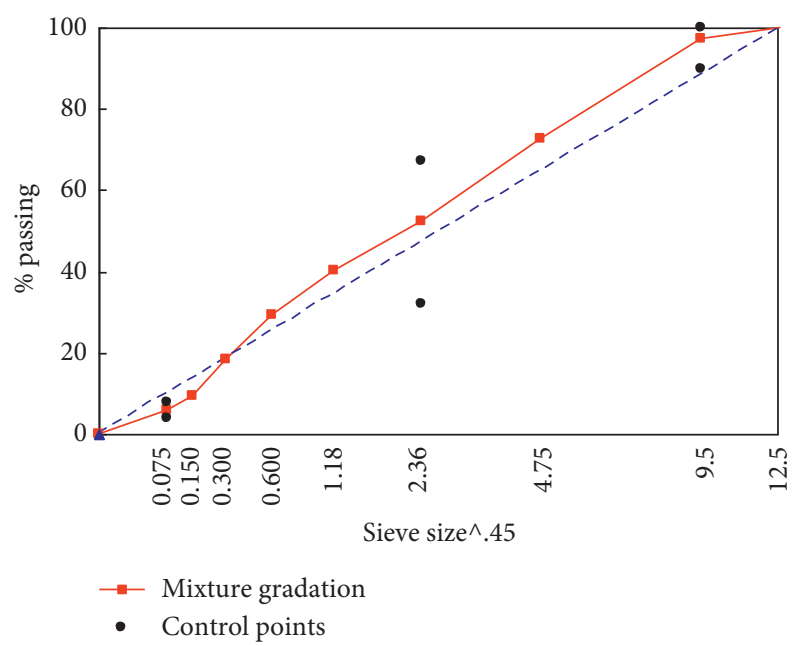

Figure 1: Mixtures gradation chart.

TABle 1: Asphalt binder test results for Superpave grade.

\begin{tabular}{lcccc}
\hline Sample ID & KS & K1 & K2 & K4 \\
\hline SBS type & - & KTR- & KTR- & KTR- \\
SBS content (\%) & 0 & 101 & 201 & $401 \mathrm{H}$ \\
Performance grade & PG70-22 & PG76-22 & PG76-22 & PG76-22 \\
\hline Original binder & & & & \\
Viscosity $\left(\mathrm{cps}, 135^{\circ} \mathrm{C}\right)$ & 612 & 2,300 & 1,800 & 2,200 \\
$G^{*} / \sin \delta\left(\mathrm{Pa}, 70^{\circ} \mathrm{C}\right)$ & 1,100 & 4,100 & 4,400 & 9,200 \\
$G^{*} / \sin \delta\left(\mathrm{Pa}, 76^{\circ} \mathrm{C}\right)$ & 500 & 2,100 & 2,200 & 4,900 \\
\hline$R T F O$ & & & & \\
$G^{*} / \sin \delta\left(\mathrm{Pa}, 70^{\circ} \mathrm{C}\right)$ & 2,900 & 9,700 & 11,200 & 17,300 \\
$G^{*} / \sin \delta\left(\mathrm{Pa}, 76^{\circ} \mathrm{C}\right)$ & 1,400 & 5,400 & 6,100 & 9,000 \\
\hline$P A V$ & & & & \\
$G^{*} \times \sin \delta\left(\mathrm{kPa}, 28^{\circ} \mathrm{C}\right)$ & 2,200 & 1,300 & 2,000 & 3,300 \\
Stiffness $\left(\mathrm{MPa},-12^{\circ} \mathrm{C}\right)$ & 142 & 143 & 149 & 144 \\
$m$-value $\left(-12^{\circ} \mathrm{C}\right)$ & 0.32 & 0.32 & 0.34 & 0.31 \\
\hline
\end{tabular}

Mineral Aggregate. To determine the compaction temperature and mix temperature for making specimens, the test for kinematic viscosity was carried out as shown in Table 2 . The mix temperature and compaction temperature for general asphalt binder are $165^{\circ} \mathrm{C}$ and $155^{\circ} \mathrm{C}$, respectively. However, the results for SBS-modified asphalt binder are higher than those for general asphalt binder. This is for the properties of SBS-modified agents. The methods for it were recently proposed for matching the site conditions as high temperature for mixing and paving the pavement. With these methods, the temperature for making SBS-modified asphalt mixtures is similar to the temperature for general asphalt mixtures. Therefore, the mixing and compacting temperatures for making some specimens were based on the results of the general asphalt binders to minimize the problems occurring at the process for making mixtures.

All mixtures having a diameter of $150 \mathrm{~mm}$ and a height of $178 \mathrm{~mm}$ were built to develop the VEPCD models by Servopac Superpave gyratory compactor made by IPC Global of Australia. The specimens used in the tension test 
TABLE 2: Asphalt binder viscosity test results by rotational viscometer.

\begin{tabular}{lcccc}
\hline Sample ID & $\begin{array}{c}\text { Temperature } \\
\left({ }^{\circ} \mathrm{C}\right)\end{array}$ & $\begin{array}{c}\text { Spindle } \\
\text { number }\end{array}$ & $\begin{array}{c}\text { Speed } \\
(\mathrm{rpm})\end{array}$ & $\begin{array}{c}\text { Viscosity } \\
(\text { Pa-sec })\end{array}$ \\
\hline \multirow{2}{*}{ KS } & 135 & 21 & 20 & 546 \\
& 165 & 21 & 50 & 147 \\
\hline \multirow{2}{*}{ K1 } & 135 & 21 & 20 & 2058 \\
& 165 & 21 & 50 & 530 \\
\hline \multirow{2}{*}{ K2 } & 135 & 21 & 20 & 1723 \\
& 165 & 21 & 50 & 424 \\
& 135 & 27 & 20 & 347 \\
\multirow{2}{*}{ K4 } & 165 & 27 & 50 & 91 \\
\hline
\end{tabular}

were cut and cored to required size with a diameter of $75 \mathrm{~mm}$ and height of $150 \mathrm{~mm}$. The constant void ratio can be obtained by cutting the outside of mixtures. The detailed information for making specimen for the tension test is presented in previous researches $[2,3]$. The mixtures for the tension test were measured for obtaining the void ratio using the CoreLok method and were housed in a plastic bag to prevent from aging at room temperature. The void ratios of the specimens were in the range from $3.5 \%$ to $4.5 \%$. Also, all specimens must not be kept for at least two weeks.

3.2. Testing Method. Specimens were bonded on steel end plate using DEVCON steel putty before performing the test, and the residues on the side of the specimen were removed to enhance the bond strength. And the bonding jig was utilized to locate accurately the specimens. When comparing with the tension test, the rubber membrane having a thickness of $0.3048 \mathrm{~mm}$ and diameter of $100 \mathrm{~mm}$ and antifriction were used between a specimen and end plate at the triaxial compression test. It is used to minimize the end effect which can be occurred between the side of the specimen and the end plate. The axial strain was measured when the tension test and compression test have been conducted.

The axial strain was measured using loose-core LVDT of $100 \mathrm{~mm}$ which is attached to the center with $90^{\circ}$. The load, displacement of crosshead, and deformation of a specimen were obtained using the National Instrument hardware and Labview software.

At the tension test, MTS (Materials Testing System) closed-loop servohydraulic system and load cell having either $11 \mathrm{kN}$ or $100 \mathrm{kN}$ were used according to the test conditions. Temperature in the chamber was controlled using liquid nitrogen. The triaxial compression test was conducted using UTM-25 (Universal Testing Machine), which has provided good results. MTS and UTM-25 machines are shown in Figures 2 and 3, respectively.

The tests can be classified as a defective test and a nondefective test. The nondefective test is to specialize linear viscoelasticity in the tension state. The nondefective test is dynamic modulus test which is based on AASHTO TP-62 [4]. Five control temperatures were used: $-10^{\circ} \mathrm{C}, 5^{\circ} \mathrm{C}$,

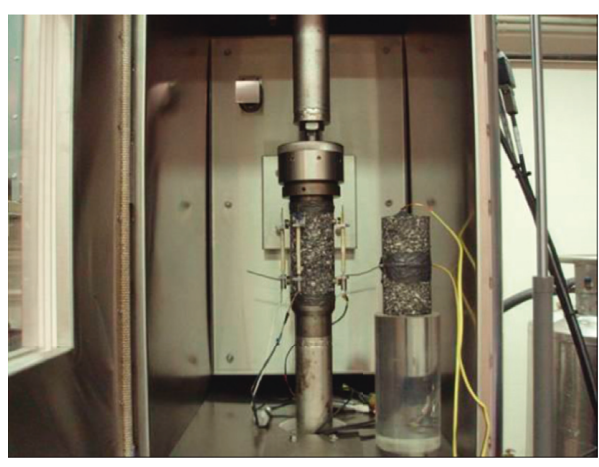

(a)

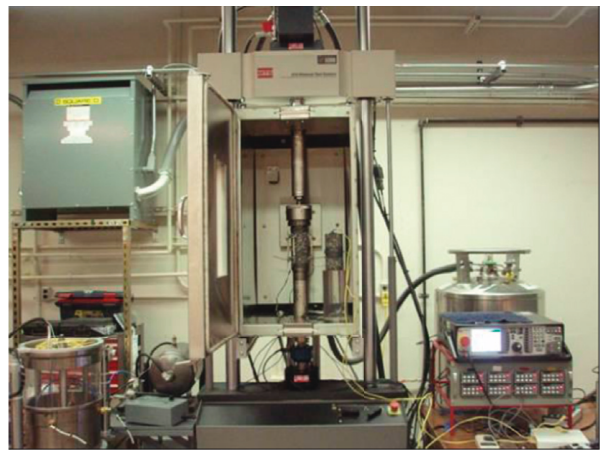

(b)

FIgURE 2: (a) Instrumented tension test specimen and (b) MTS machine.

$20^{\circ} \mathrm{C}, 40^{\circ} \mathrm{C}$, and $54^{\circ} \mathrm{C}$, and six load frequencies were applied: $25 \mathrm{~Hz}, 10 \mathrm{~Hz}, 5 \mathrm{~Hz}, 1 \mathrm{~Hz}, 0.5 \mathrm{~Hz}$, and $0.1 \mathrm{~Hz}$. The loading load was selected about 50 75 microstrain at each condition. The defective test had been conducted to develop the model regarding rutting and cracking and to verify the model. At the tension test, the constant crosshead rate test and the cyclic load test were conducted. The constant crosshead rate test was accomplished to specialize the materials using constant crosshead strains at two temperature conditions of $5^{\circ} \mathrm{C}$ and $40^{\circ} \mathrm{C}$. The cyclic load test is usually conducted as a method for controlling the load or displacement. The controlled crosshead cyclic loading test was conducted in this research. It uses the mixed load which is to control neither load nor displacement to a specimen. Usually, it is similar to the real site condition of the load. The crosshead cyclic loading test of the displacement control method was conducted by utilizing the constant loading method of $10 \mathrm{~Hz}$ at $19^{\circ} \mathrm{C}$. The triaxial compression test for plastic deformation was conducted using the constant confine stress and effective pressure at temperatures of $40^{\circ} \mathrm{C}$ and $54^{\circ} \mathrm{C}$.

\section{Evaluation of Fatigue Cracking}

As mentioned before, the VEPCD model related to the viscoelastoplasticity continuum failure was used. The VEPCD model is the expanded type from VECD (viscoelastic continuum damage) and has some advantages that it can predict the behavior of asphalt mixtures with a wide 


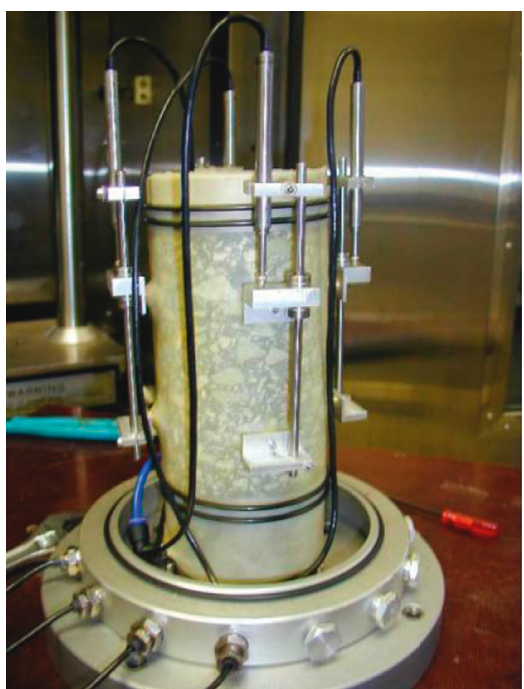

(a)

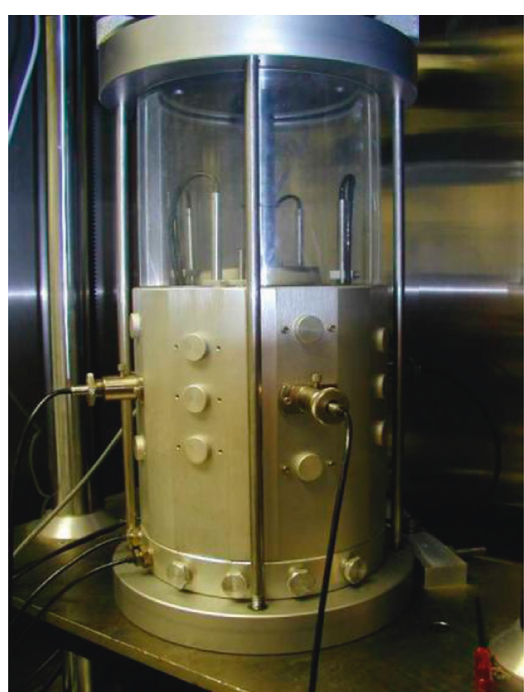

(b)

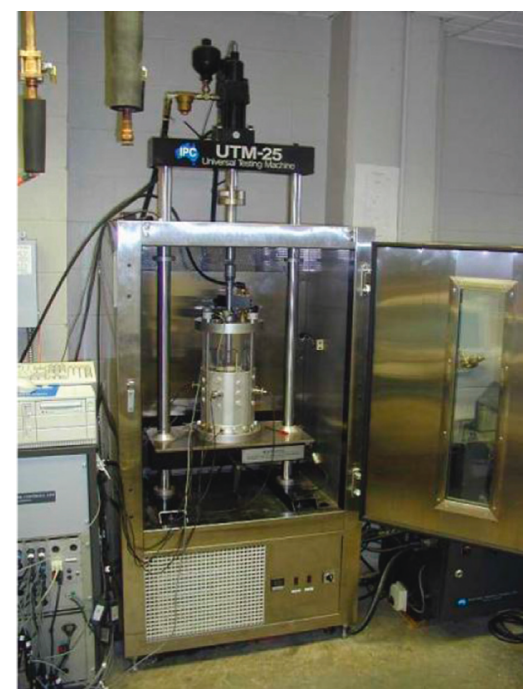

(c)

FIgURE 3: (a) Instrumented TRLPD specimen, (b) triaxial cell, and (c) UTM-25 machine.

range of traffic and environmental load from the relatively simple and few test results.

4.1. Development of Linear Viscoelastic Model. The properties of asphalt mixtures used in this research are shown and listed below. Figure 4 indicates the master curves for determining the dynamic modulus $\left(\left|E^{*}\right|\right)$ of mixtures with semilog and $\log$-log scales. The high frequency means relatively it is at low temperature and fast load. The opposite, low frequency, means the reverse situation comparing to the high frequency. It has been widely known that the materials having either high stiffness with low damping frequency or low stiffness with high damping frequency are generally strong to resist the cracking and rutting.

The properties at the high damping frequency can be precisely seen in Figure 4(a). KS and K4 mixtures have larger stiffness than $\mathrm{K} 1$ and $\mathrm{K} 2$ mixtures. But it makes no odds. The master curve for KS mixture has a relatively sharp slant in the transition section compared to SBS-modified asphalt mixtures. The slope of the master curve can be used by index $(m)$ for the temporal dependency of a material. In the transition section, the sharp slant means that the material has large temporal dependency and the gentle slope means that it is on elastic behavior. The KS mixture has consequently lowest stiffness at low damping frequency as shown in Figure 4(b). In another condition of frequency, the inverse result can be seen. The master curve of dynamic modulus for $\mathrm{K} 1$ and $\mathrm{K} 2$ mixtures indicates that the specimens have almost the same properties. But the dynamic modulus of K1 material is higher than that of K2 mixture at hightemperature condition. This means that $\mathrm{K} 2$ mixture is better to rutting than K1 mixture.

In only dynamic modulus test excepting for the failure test, $\mathrm{K} 1$ and $\mathrm{K} 2$ mixtures seem to retain fine balance related to cracking and rutting. The KS mixtures can be at risk for having lower commonness like cracking and rutting than others because of the dynamic modulus results. The K4 materials stand a chance of having high resistance from rutting because it takes the high dynamic modulus at high temperature.

The elastomeric modifier added to SBS-modified asphalt mixture was used for improving the elastic property of asphalt mixtures. It can be evaluated by using the phase angle of the master curve. According to the viscoelastic theory, small angle means large elastic property. The phase angles for the four types of mixtures using the average of results from specimens are shown in Figure 5. The mixtures have similar elastic properties at the low-temperature condition. As the temperature has risen, the elasticity of KS mixtures was low and the viscosity was high. As expected, K4 mixtures have the strongest property of elasticity and K1 mixtures and $\mathrm{K} 2$ mixtures are middle of them.

These phenomena had been changed as the temperature had risen. This phenomenon can be seen in the low reduced frequency (below 10-5) as shown in Figure 5. At this section, KS mixtures have higher elasticity than others. It is change phenomenon that the changes of phase angle patterns were dominant with the used binder at either low temperature or room temperature and it can gradually be changed when the condition was at high temperature. At this time, the changes of phase angle patterns were dominant with the used aggregates. The phase angle of the mixtures becomes small because the aggregates are elastic material. This is a good phenomenon that the mixtures have high phase angle at high temperature. The high phase angle at high temperature is a reason that the effective service temperature is higher than other cases because of the binding force of modified agents. The time for rearranging the molecules of material can be relatively slow at low reduced frequency. At that time, the binding force of materials is stronger than before. With the similar concept, the binding force is not clearly eliminated but gradually decreased due to not enough time for determining the directions of molecules at the fast reduced 


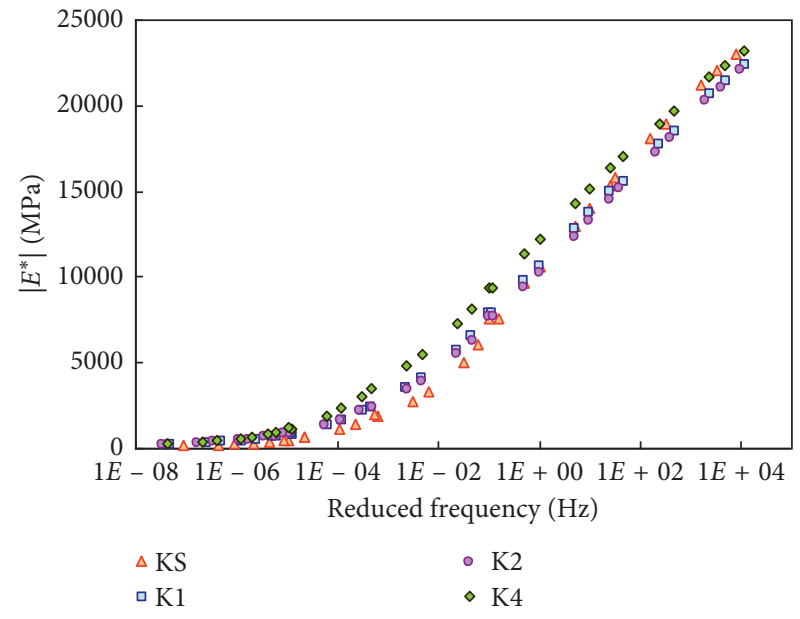

(a)

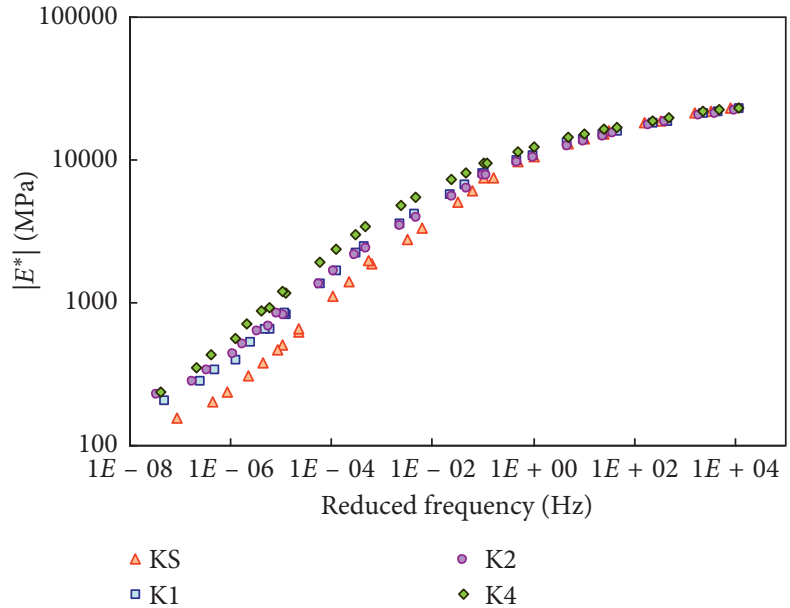

(b)

Figure 4: Dynamic modulus master curves for all four mixtures in (a) semilog space and (b) log-log space.

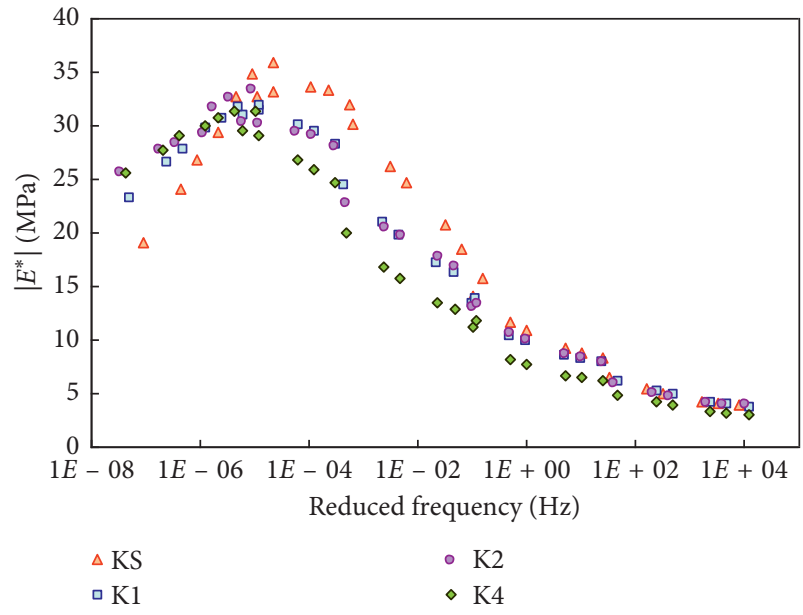

FIgURE 5: Phase angle master curves for all four mixtures.

frequency [5]. The shift factors related to the loading frequency and temperature are presented in Figure 6. It indicates that the shift factors of SBS-modified mixtures are slightly lower than that of KS mixture.

The intercepts of the minimum and maximum asymptotic curves for master curve were, respectively, noted as $E 0$ and $E \infty$ in Table 3. $m$ means the max slope of the master curve in logarithm mix space. These values indicate the typical characteristics such as the elastic stiffness, max stiffness, and general temporal dependency of mixtures obtained from the sigmoidal fitting.

4.2. Development of Viscoelastic Damage Model. In this research, the constant crosshead rate test which is one of the simplest tests was conducted to develop the failure model of viscoelastic mixtures. As the latest research results of ours, the failure models can be developed with the results from the cyclic fatigue test, and it can directly evaluate the performance about the failure of a mixture [6]. The advantage of

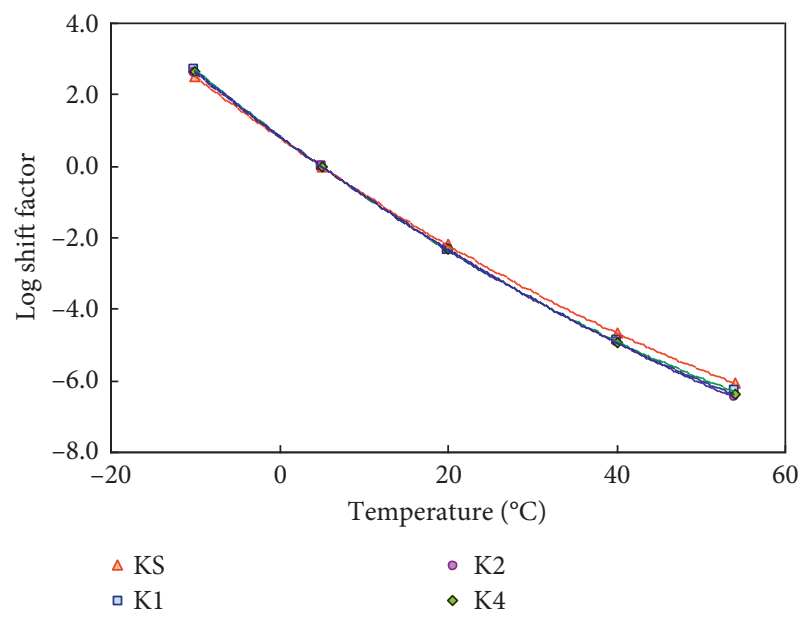

Figure 6: Log shift factor function for all four mixtures.

TABLE 3: Linear viscoelastic quantities for all four mixtures.

\begin{tabular}{lcccc}
\hline Parameters & KS & K1 & K2 & K4 \\
\hline$m$ & 0.317 & 0.289 & 0.271 & 0.295 \\
$E_{0}(\mathrm{MPa})$ & 25990 & 24637 & 25541 & 25715 \\
$E_{\infty}(\mathrm{MPa})$ & 51 & 46 & 51 & 24 \\
\hline
\end{tabular}

the cyclic fatigue test is that it is possible to carry out the experiment using the Asphalt Mixture Performance Tester (AMPT) which is newly made in the USA. It is impossible to conduct the constant crosshead rate test because it uses the smaller load cell than UTM to reduce the cost of AMPT. Therefore, the failure models for the four types of mixtures were developed by carrying out the constant crosshead rate test in this research according to the future trend of asphalt market for the USA.

The important results and test conditions for the constant crosshead rate test are summed up in Table 4. In this test, the cycle load was constantly applied by using the 
TABle 4: Cyclic fatigue test summary.

\begin{tabular}{|c|c|c|c|c|c|c|}
\hline $\begin{array}{l}\text { Mix } \\
\text { ID }\end{array}$ & $\begin{array}{l}\text { Specimen } \\
\text { ID }\end{array}$ & $\begin{array}{c}\text { Test } \\
\text { designation }\end{array}$ & $\begin{array}{l}\text { Initial stress }(\mathrm{kPa}) \text {-tension } \\
\text { amplitude }^{\mathrm{d}}\end{array}$ & $\begin{array}{l}\text { Initial strain (microstrain)-peak } \\
\text { to peak }^{\mathrm{d}}\end{array}$ & $\begin{array}{l}\text { Frequency } \\
\quad(\mathrm{Hz})\end{array}$ & $\begin{array}{l}\text { Cycle } \\
\text { at failure }\end{array}$ \\
\hline \multirow{2}{*}{ KS } & KS-205 & $19^{\mathrm{a}}-\mathrm{CX}^{\mathrm{b}}-\mathrm{H}^{\mathrm{c}}$ & 1788 & 424 & 10 & 8,821 \\
\hline & KS-202 & 19-CX-L & 1552 & 247 & 10 & 69,008 \\
\hline \multirow{2}{*}{ K1 } & K1-205 & 19-CX-H & 1717 & 391 & 10 & 10,856 \\
\hline & K1-208 & 19-CX-L & 1514 & 319 & 10 & 206,186 \\
\hline \multirow{2}{*}{$\mathrm{K} 2$} & K2-204 & 19-CX-H & 1749 & 429 & 10 & 21,387 \\
\hline & K2-206 & 19-CX-L & 1658 & 307 & 10 & 224,764 \\
\hline \multirow{2}{*}{ K4 } & K4-202 & $19-\mathrm{CX}-\mathrm{H}$ & 1950 & 308 & 10 & 2,731 \\
\hline & K4-203 & 19-CX-L & 1499 & 219 & 10 & 83,370 \\
\hline
\end{tabular}

${ }^{a}$ Test temperature in degree Celsius. ${ }^{\mathrm{b}}$ Test mode. ${ }^{\mathrm{c}}$ Relative magnitude: $\mathrm{H}=$ high, $\mathrm{L}=$ low. ${ }^{\mathrm{d}}$ Initial stress and strain amplitude are the average of first 5 cycles.

crosshead repeatedly. The number of cycled loads to the failure was based on the standard for the rapidly diminished phase angle. To evaluate the fatigue performance of mixture, relations between the initial strain and the number of the cycled loads to failure were used. The analysis result for evaluating the performance obtained from the empirical method using the four types of mixtures is shown in Figure 7. As seen in Figure 7, K4 mixture has most rapidly reached the failure in the heavy load condition (large initial strain that the initial strain indicates 400 microstrain). Then has reached K1, KS, and K2 in that order. But KS and K4 mixtures have reached the failure with the similar number in the light load condition (small initial strain that the initial strain indicates 200 microstrain). Then comes $\mathrm{K} 2$ and $\mathrm{K} 1$ in that order. We can predict the performance using these results. The performance evaluation method using the empirical method depends on what variables were used. Also, it has disadvantage that it is difficult to find the direct correlation with the performance of the constructed pavement and it cannot be used for the final result. In this research, the performance of the constructed pavement was predicted using VECD-FEP++ which is developed from VECD applying the FEM (finite element method). It is listed in the next section.

The damage characteristic curve using the results from the cycle load test regarding the failure of mixtures is shown in Figure 8. We had the results from the cycle load test about each of the mixtures, and the repeatability of specimens is in good state. Also, it is very similar to the damage characteristic curve obtained from the results of the constant crosshead test. As an important thing in Figure 8, the values of $C^{*}$ (pseudostiffness) at the failure can be different with the mixture types. For examples, KS, K1, and K2 mixtures were destructed at the similar values of $C^{*}$, but K4 had a higher value of $C^{*}$ than others (Table 5). These outcomes can be utilized to analyze the performance of the constructed pavement using FEM.

The average damage characteristic curve for comparing each other can be seen in Figure 9. K4 mixture has been indicated as the most desirable damage characteristic curve in this figure. Then comes K1, K2, and KS in order. Finally, we can conclude the damage characteristic for KS mixture is worst. But the performance of the mixtures cannot be determined using only these curves; the influence of effecting

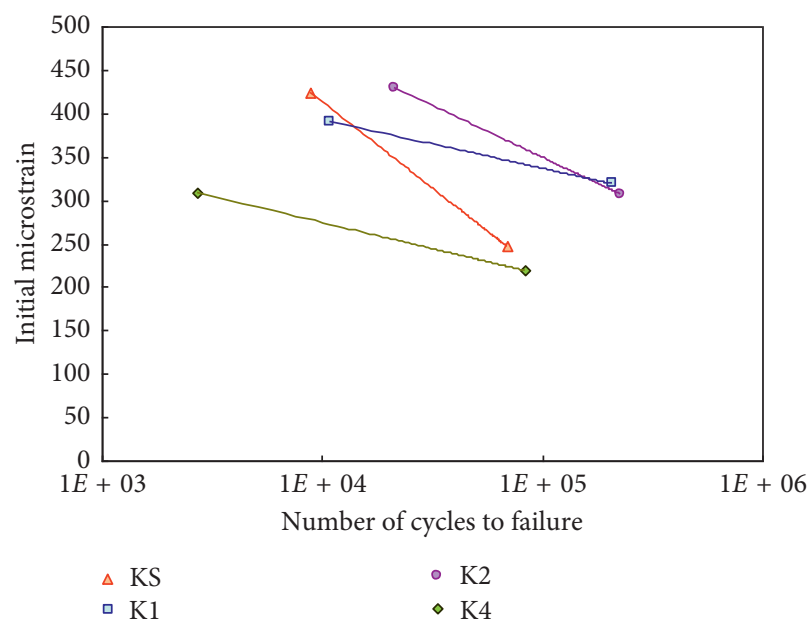

FIgURE 7: Initial microstrain versus number of cycles to failure for all four mixtures.

the pavement and the resistances for deformation and damage are always concerned for evaluating the resistance of fatigue failure of asphalt mixture. In the next section, the analysis results related to the resistance of fatigue cracking using VECD-FEP++ were suggested. This evaluation is the only way to analyze the effect of material properties on the pavement and the resistances for damage and deformation of mixtures.

4.3. Pavement Analysis Method. The pavement structures which are different from each other were considered to evaluate the performance using VECD-FEP++. The first structure that it is equal to the general asphalt pavement was comprised of a subgrade assumed as the infinite depth, a subbase of $200 \mathrm{~mm}$, and an asphalt layer of $100 \mathrm{~mm}$. The second structure had an infinite subgrade layer and a thick asphalt layer of $300 \mathrm{~mm}$. The material properties of the asphalt layer analyzed using VECD model were used, and the substratum and subgrade were supposed to have linear elasticity. The temperature of $19^{\circ} \mathrm{C}$ was applied to all analysis. The moving load has haversine of $0.1 \mathrm{sec}(10 \mathrm{~Hz})$ and recovery time of $0.9 \mathrm{sec}$. The load and pressure of $40.034 \mathrm{kN}$ and $827.37 \mathrm{kPa}$ that have been generally used in the analysis of thin pavement were applied. The load and pressure of 


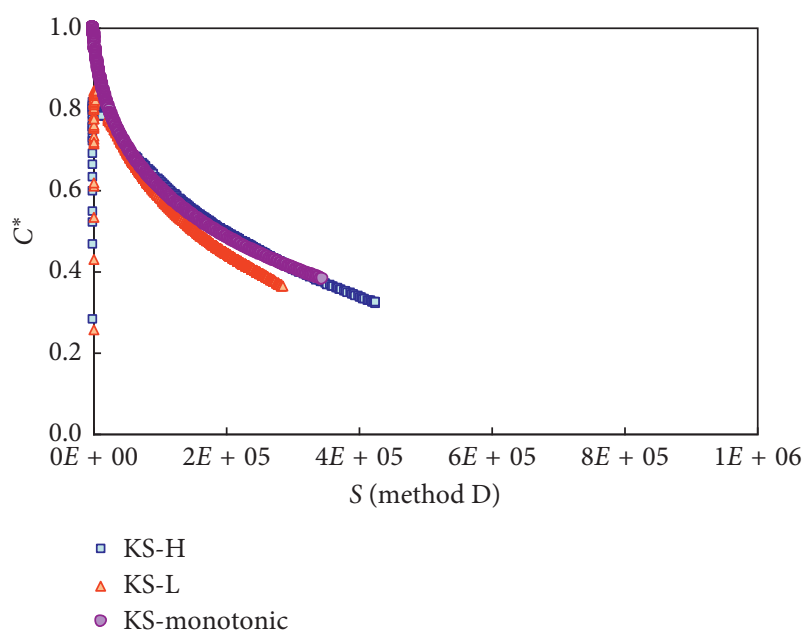

(a)

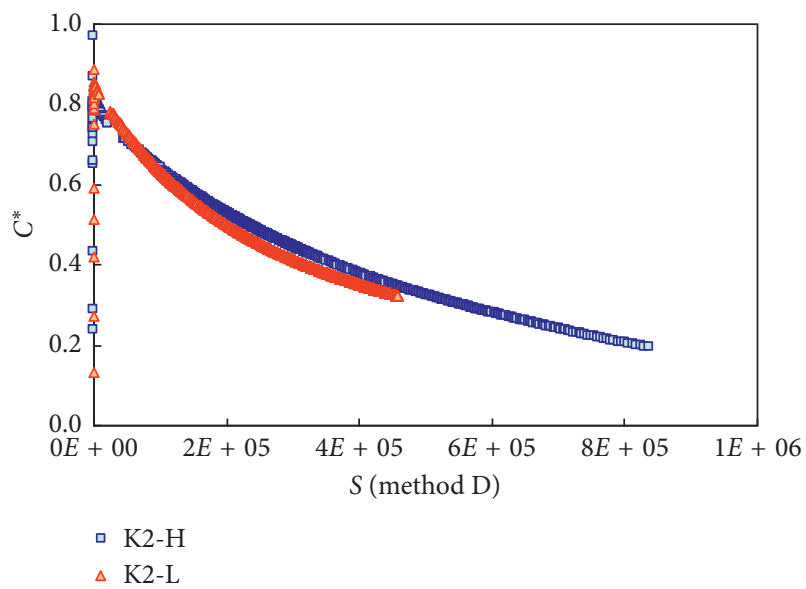

(c)

Figure 8: Damage characteristic curves of (a) KS, (b) K1, (c) K2, and (d) K4 mixtures.

TABLe 5: $C^{*}$ values at failure $\left(C_{\mathrm{f}}\right)$ from cyclic fatigue test.

\begin{tabular}{lccc}
\hline \multirow{2}{*}{ Mix ID } & \multicolumn{2}{c}{ Loading amplitude } & Average \\
& $H$ & $L$ & 0.34 \\
KS & 0.32 & 0.36 & 0.35 \\
K1 & 0.43 & 0.26 & 0.26 \\
K2 & 0.19 & 0.32 & 0.53 \\
K4 & 0.56 & 0.50 &
\end{tabular}

$73.8426 \mathrm{kN}$ and $827.37 \mathrm{kN}$ were applied to accelerate the failure with analysis of the thick pavement at the general load. The moduli of elasticity for substratum and subgrade are, respectively, $150,000 \mathrm{kPa}$ and $35,000 \mathrm{kPa}$. The number of cycle loads was 50,000,000 for the thin pavement and was $100,000,000$ for the thick pavement.

The extrapolation was developed to conduct the pavement analysis loading a number of cycle loads in adequate time. The extrapolation means that the loading could be skipped instead of applying the number of cycle loads already selected and extrapolating the results of the previous load. The extrapolation of the cycled load can be applied

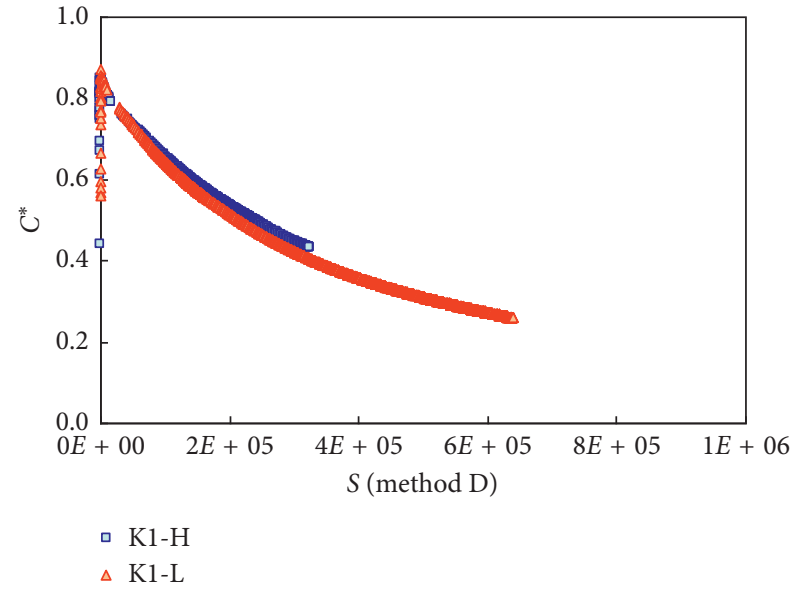

(b)

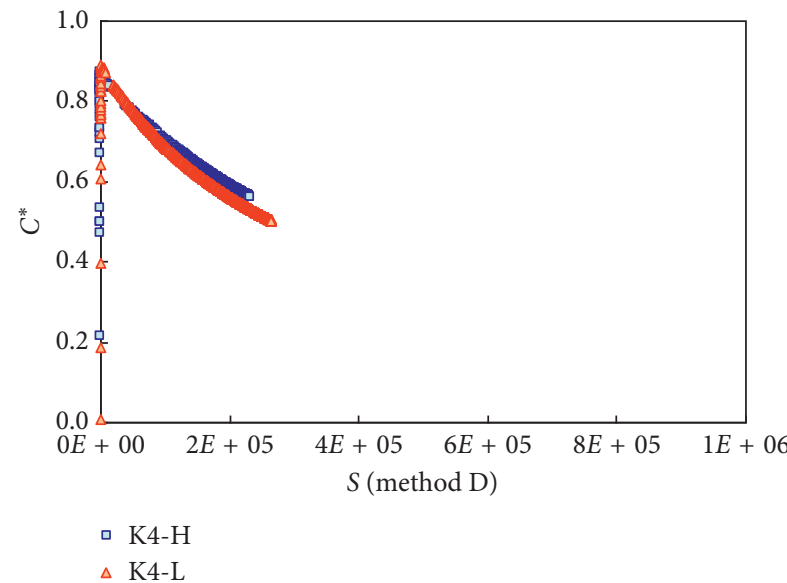

(d)

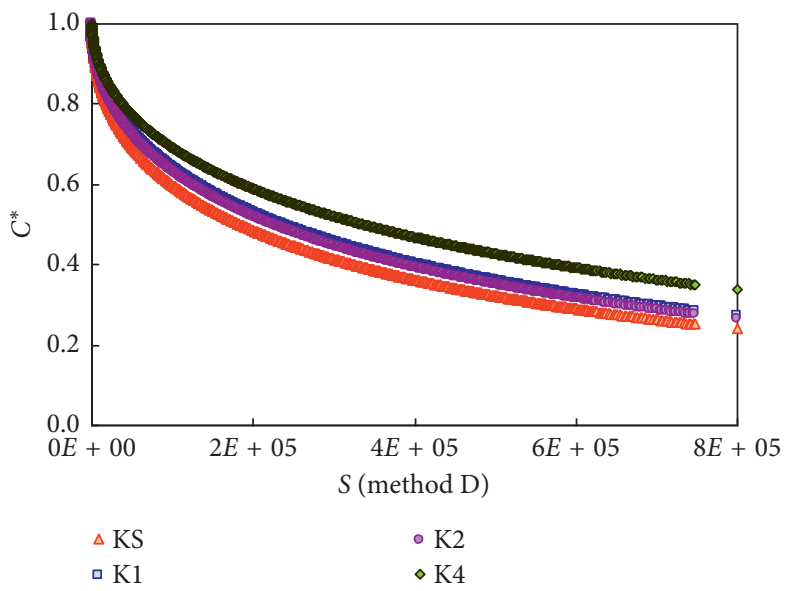

FIGURE 9: Damage characteristic curves for all four mixtures.

because the property of asphalt commonly indicates the linearity. The extrapolation and constitution of finite element mesh were decided using the sensitive analysis. The finite element analysis was conducted with the horizontal length of 
TABLe 6: Contour plots of $C$ for thin pavements in color mode.

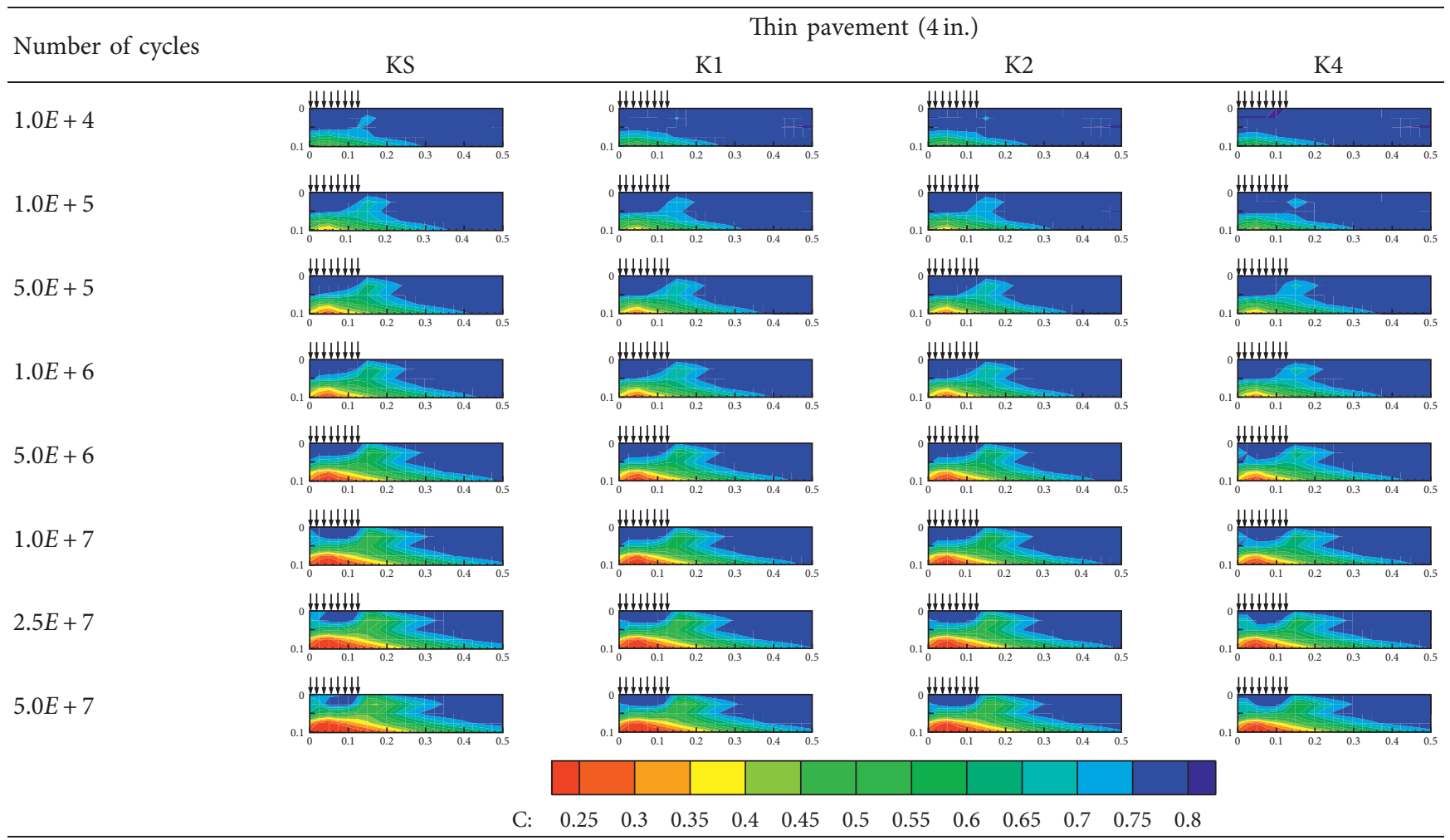

$1 \mathrm{~m}$ from the center of the load and the depth to the infinite subgrade. The special element was utilized to minimize the analysis time and effect from the infinite boundary.

4.4. Pavement Analysis Results. The results of $C$ value which means the damage increment of pavement per increment of cycle load are shown in Table 6. The values of $C$ were from VECD-FEP++ that it is usually for the thin pavement structures. The analysis results for the thick pavement structures are shown in Table 7 . Where, the more $C$ value is small, the more it means the significant damage. The arrows on pavement indicate the loading points. The axisymmetric analysis was used for analyzing the pavement.

In these tables, we can simply figure out that the failures transmitted from the bottom of the pavement to the upper layer. This phenomenon looks like the bottom-up fatigue cracking occurred frequently in the thin pavement structures in sites. By comparing the pavement performance with each other, the pavement of KS mixture can be more damaged than others in thin and thick layers. Then comes K1, K2, and $\mathrm{K} 4$ in that order. But to compare the performance of pavements with each other is hard due to the minor damage of each mixture.

The index for damage area was utilized to easily compare the performance using the degree for the bulk of damages. The damaged area can be usually calculated that the number of nodes for finite elements is divided by the number of total nodes when the value of $C$ is under 0.25 . Where, the total number is based on the length that it is horizontally $5 \mathrm{~m}$ from the center and depth that is vertically to the bottom of the asphalt layer. Also, the value of $C$ indicates generally 0.25 when the strain reached localization point at the constant velocity crosshead test. Therefore, the small damaged area has the better performance. The result of the pavement analysis is shown in Figure 10 using the percentage of the damaged areas. It shows the results of the damaged area calculated using the standard $C$ value of 0.5 because the damaged area under the $C$ value of 0.25 is similar to that under the $C$ value of 0.5 at the thin pavement analysis. Also, the damaged area was minor at the thick pavement analysis. At any condition of depth types, we can easily conclude that the performance of pavement is superior when we were using K4 mixture and is worst when we were utilizing KS mixture.

The value of $C$ under 0.25 is assumed to all types of mixtures at the pavement analysis. However, the failure can be occurred at the different values of $C$ according to the mixture types as seen in the previous section for developing the damaged models. The results of the pavement analysis were once again analyzed considering the characteristic value of $C_{\mathrm{f}}$ regarding the mixture types.

The pavement analysis results are shown in Tables 8 and 9. Also, the percentage of the damaged area was calculated and is shown in Figure 11. The analytical outcomes using the characteristic value of $C_{\mathrm{f}}$ are considerably different with another result using the same value of $C_{\mathrm{f}}$ to the any type of mixtures. The performance for the fatigue failure of $\mathrm{K} 4$ mixture was excellent using the erstwhile methods, but it was worst when we used the new analytical method. Then comes $\mathrm{KS}, \mathrm{K} 1$, and $\mathrm{K} 2$ in order. These results are greatly similar to the method using the empirical method shown in Figure 7. 
TABLE 7: Contour plots of $C$ for thick pavements in color mode.

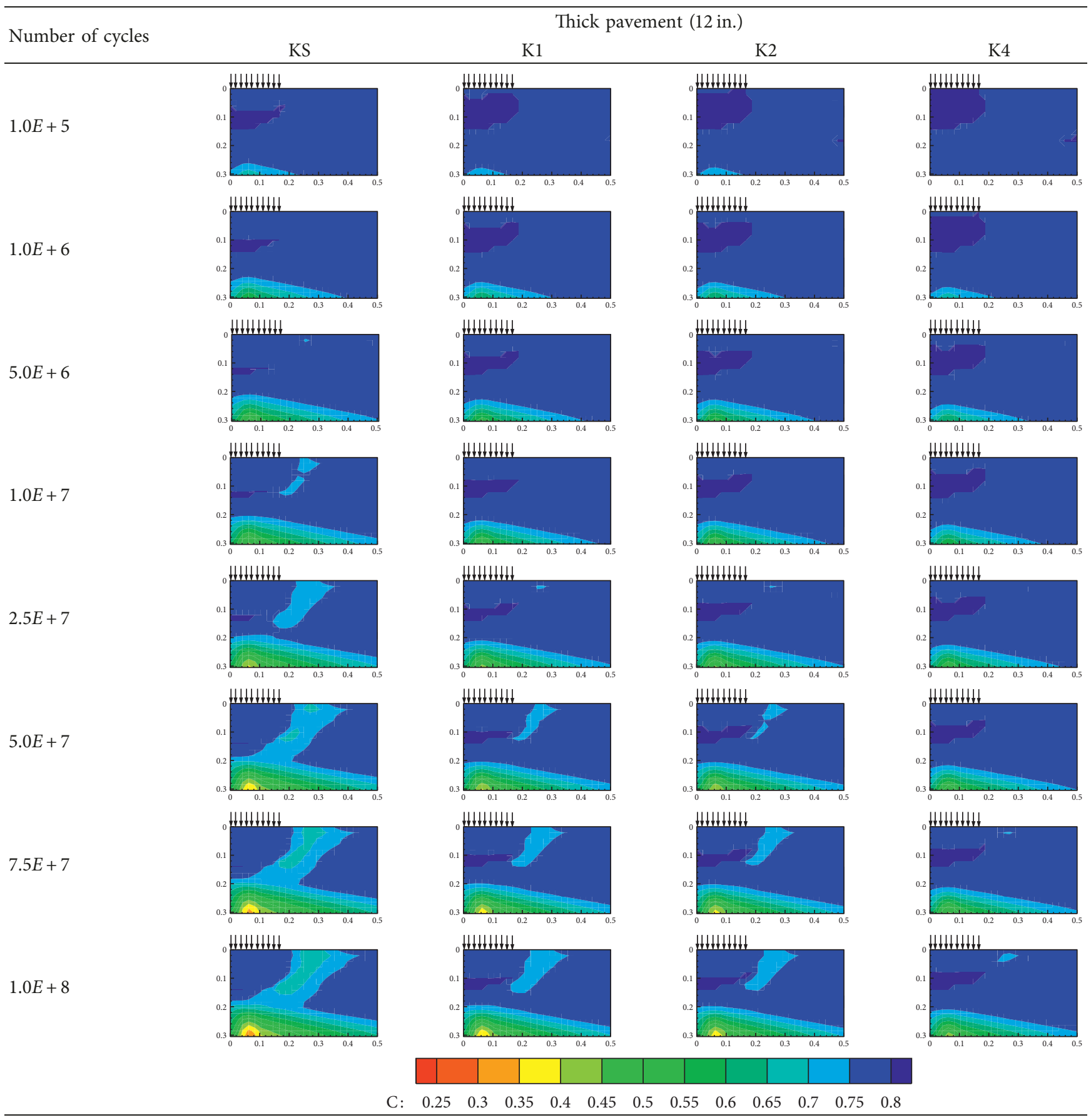

\section{Performance Evaluation on Rutting}

The performance regarding the rutting of SBS-modified asphalt mixtures was measured and analyzed using the compression and tension tests in this paper. In the results at the condition of tension, it is impossible to measure directly the viscoelasticity properties of binders because of little engagement with the aggregates. And it can precisely describe the stress states in sites. We measured the performance of rutting for modified asphalt mixtures using the results obtained from the compression and tension tests in this research.

5.1. Evaluation of Rutting Performance by Tension Test. Prior to explain the viscoplasticity properties regarding the tension load, the strain rate and temperature affecting the viscoplasticity properties are needed to make reference. The viscoplastic effect which is the function of reduced strain rate indicates the effect to the total strain rate at the standard temperature of $5^{\circ} \mathrm{C}$ shown in Figure 12. The viscoplastic 


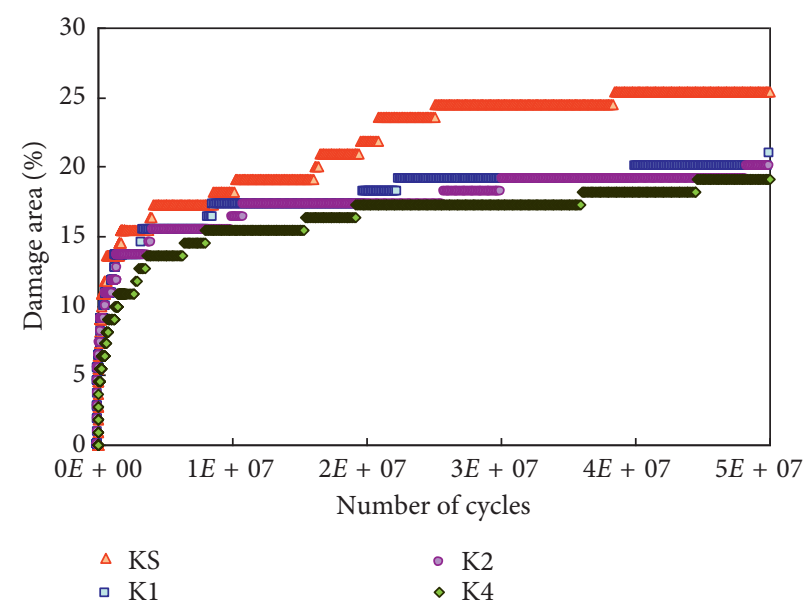

(a)

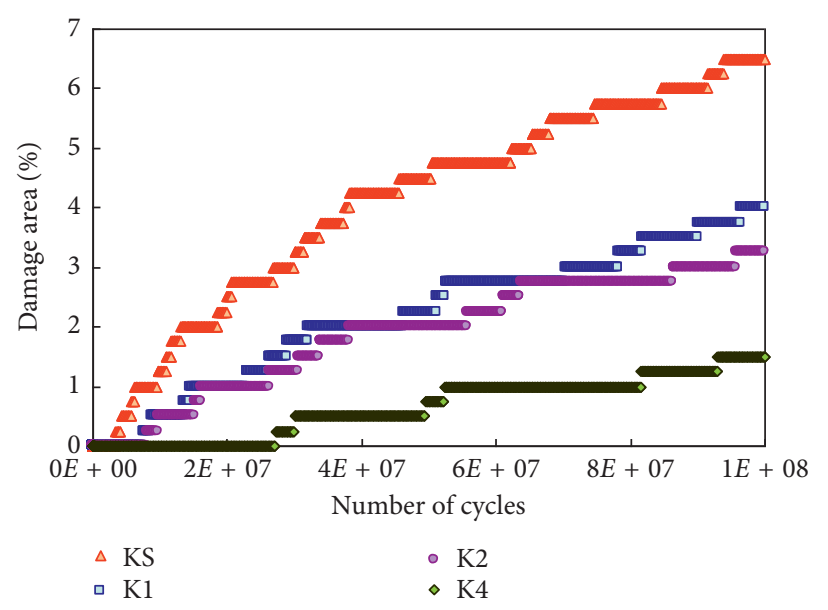

(b)

FIgURE 10: Damage area (\%) along number of cycles for (a) thin pavement and (b) thick pavement.

TABle 8: Modified contour plots of $C$ for thin pavements in color mode.

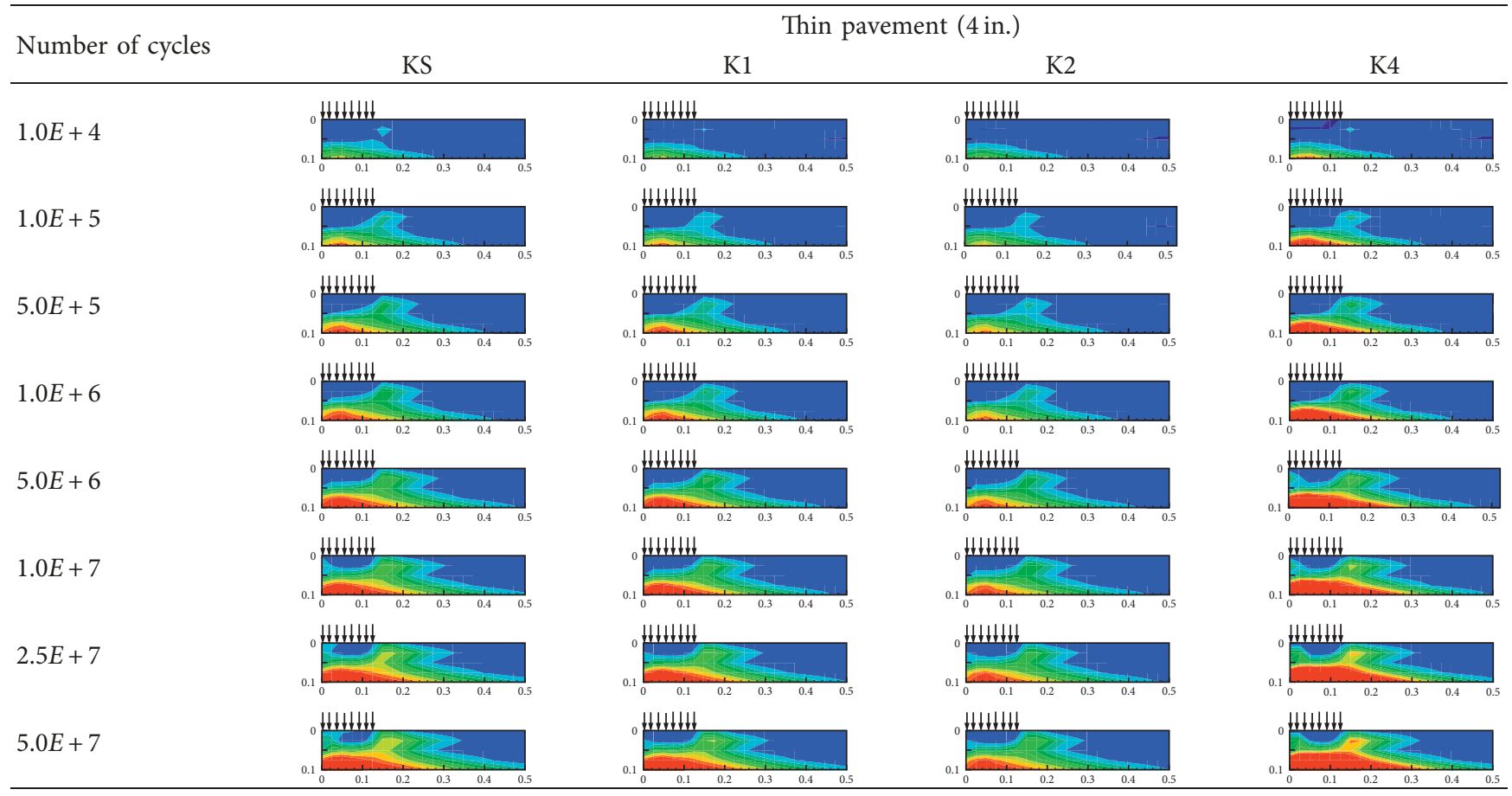

properties related to the effect of material behaviors were conducted using the constant crosshead test. The background of the theory and experiment for curves are referred in various studies $[1,6-14]$. The points in this figure indicate the viscoplastic strain rates at the maximum stress in the test applying the strain rate and temperature. The properties for the K2 mixture were summarized through other tests because it was tested in the constant crosshead test using two types of the reduced frequency ratio.

To understand the results shown in Figure 12, it is important to grasp the relationship between the loading rate and temperature. The strain rate is high as either the high temperature or physically high strain and reversely low as either the low temperature or physically low strain. Therefore, the rate of the behavior for the viscoplastic materials is high when the relation between viscoplastic and reduced strain rate shown in Figure 12 is dominant with high temperature and slow loading. The strong mixture to rutting has low \% viscoplasticity. So, KS materials have the highest viscoplastic behavior comparing to other types consisting of SBS-modified agent, and K4 materials have lowest viscoplastic behavior in the condition of reduced strain. It is shown in Figure 12. However, it indicates that K1 type has the better properties regarding rutting than $\mathrm{K} 4$ mixtures in the conditions of the low slope of mixtures or high temperature or slow loading (like a parking lot condition). From the highest slope of K4, it 
TABLE 9: Modified contour plots of $C$ for thick pavements in color mode.

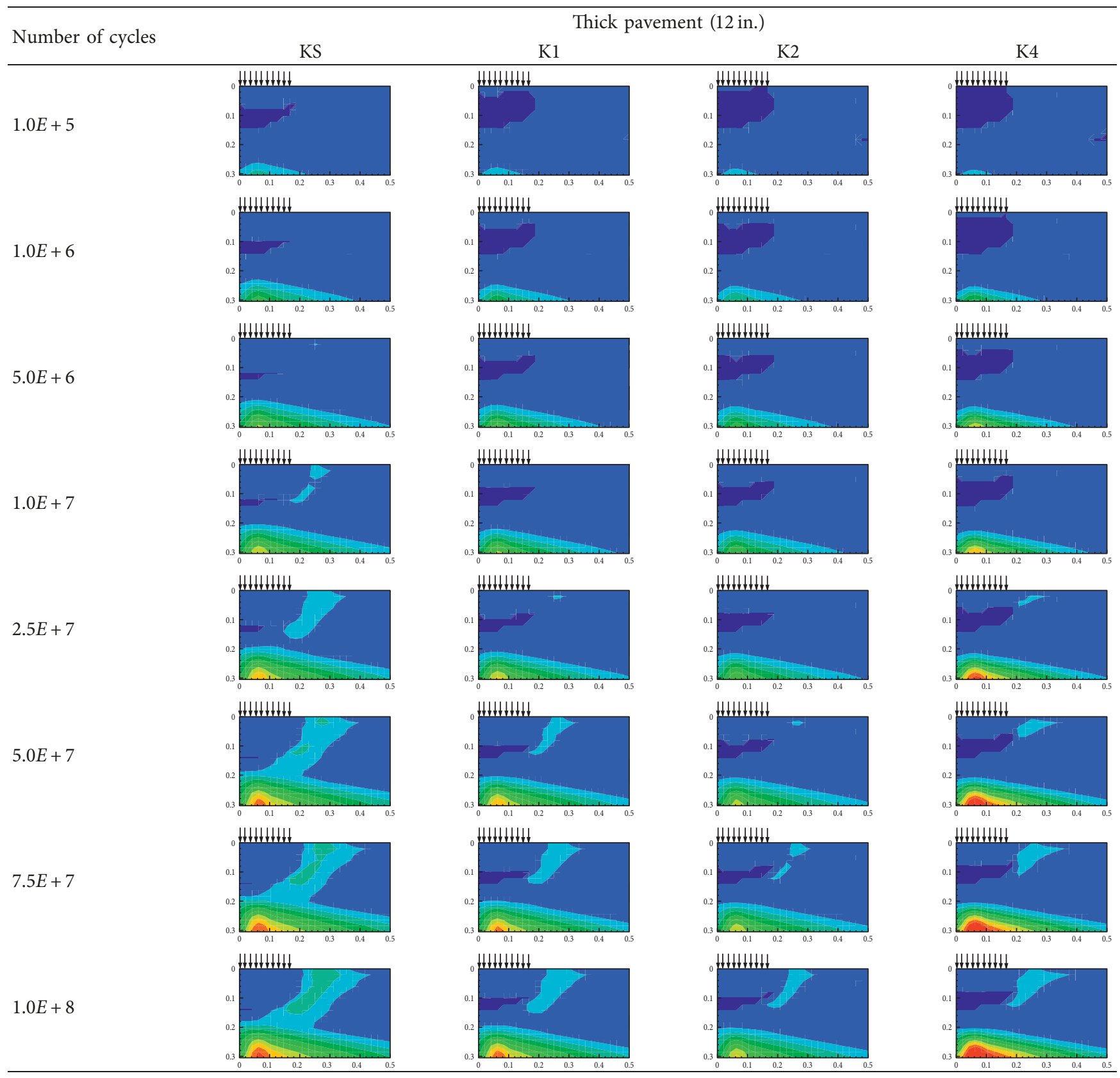

can be expected that the K4 mixture shows very small viscoplastic deformation at low temperature or fast loading condition, that is, high damping frequency, but similar viscoplastic behavior to other mixtures at high temperature or slow loading condition, that is, low damping frequency.

\subsection{Rutting Performance by Triaxial Compression Test.} The research related to rutting at the compression condition for the SBS-modified mixture and KS mixture was conducted to triaxial repeated load permanent deformation (TRLPD). It had tested at the semistructured loading of $0.1 \mathrm{sec}$ and recovery of $0.9 \mathrm{sec}$. From the NCHRP 9-30A, the stress states of $483 \mathrm{MPa}$ for deviator stress of confining pressure and the temperatures of $40^{\circ} \mathrm{C}$ and $54^{\circ} \mathrm{C}$ were recommended. The model developed from these stress conditions is called permanent-to-resilient strain ratio model. It standardizes the rutting strain to the average of recoverable strain. It has been utilized at Mechanistic-Empirical Pavement Design Guide of NCHRP 1-37A.

$$
\frac{\varepsilon_{\mathrm{p}}}{\varepsilon_{\mathrm{r}}}=K_{z} \beta_{r 1} 10^{\alpha_{1}} T^{\beta r_{2} \alpha_{2}} N^{\beta r_{3} \alpha_{3}},
$$

where $\varepsilon_{\mathrm{p}}=$ accumulated plastic strain at $N$ repetitions of load (in/in), $\varepsilon_{\mathrm{r}}=$ resilient strain (in/in), $K_{z}=\left(C_{1}+C_{2}\right.$ depth $) \times$ 


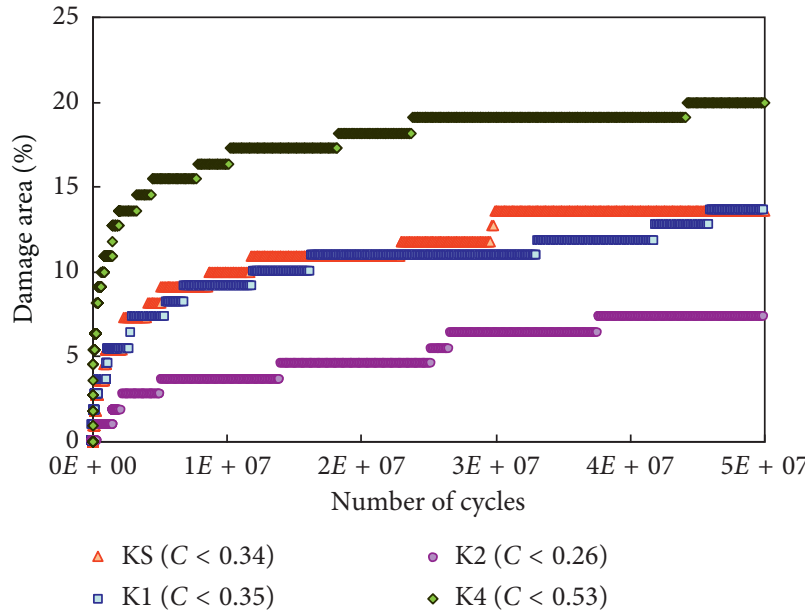

(a)

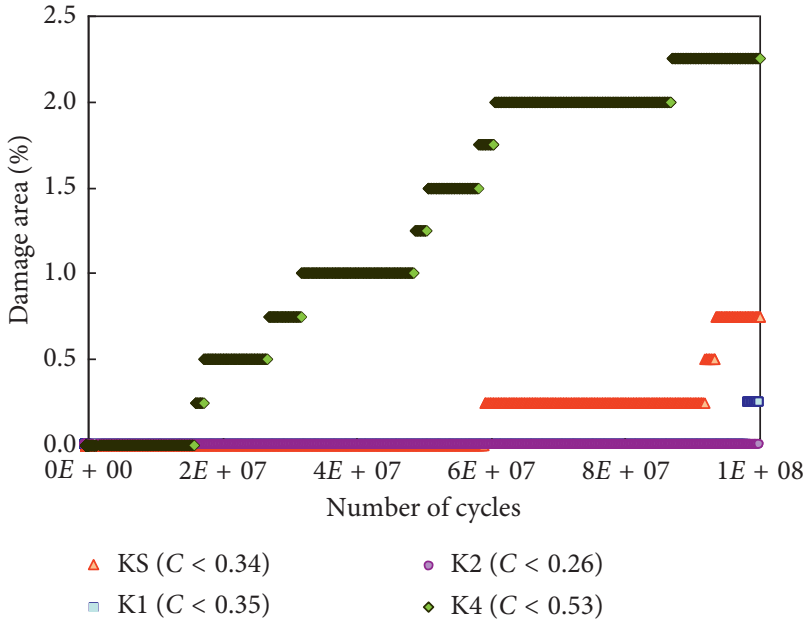

(b)

FIgURE 11: Modified damage area (\%) along number of cycles for (a) thin pavement and (b) thick pavement.

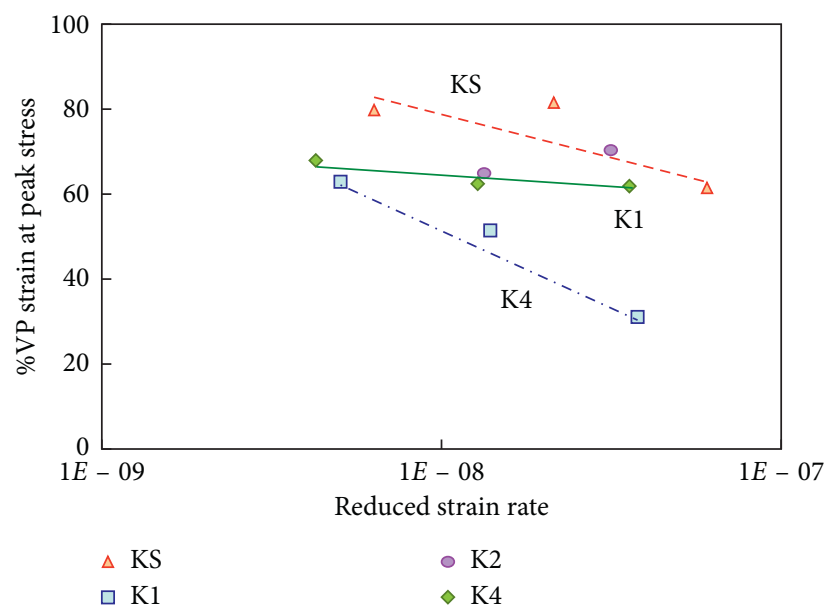

FIGURE 12: Influence of viscoplasticity on all four mixtures' behavior.

$0.328196^{\text {depth }}$, a function to correct for effect of depth on confining pressure, $\beta r_{i}=$ calibration factors, $\alpha_{i}=$ nonlinear regression coefficients, $T=$ temperature $\left({ }^{\circ} \mathrm{F}\right), N=$ number of load repetitions, $C_{1}=-0.1039 \mathrm{H}_{\mathrm{HMA}}^{2}+2.4868 \mathrm{H}_{\mathrm{HMA}}-$ $17.342, C_{2}=0.0172 H_{\mathrm{HMA}}^{2}-1.7221 H_{\mathrm{HMA}}+27.428$, and $H_{\mathrm{HMA}}=$ thickness of asphalt layer (in.).

The results obtained from TRLPD test for the four types of mixtures are shown in Figures 13 and 14. The rates for the rutting strain per recovery elastic strain of rutting strain are shown using the semilog and log-log scale. In these figures, any type of mixtures does not show the tertiary flow. It means that all mixtures have the efficient resistance to the rutting. Also, the rutting strain at $54^{\circ} \mathrm{C}$ is always bigger than that at $40^{\circ} \mathrm{C}$; it indicates that the temperature can absolutely affect the rutting strain. But the rate for the recovery elastic strain of rutting strain shown in figures means the tendency of having either minor difference or not constant. In using Equation (1), the results for the rate can be generally different with the temperatures. But in this research, the difference is very minor when testing the four types of mixtures. So, the rutting and recovery elastic rate can be similarly affected by the temperature.

Figure 13 shows the comparison for the average rutting strain of mixtures at each temperature, and Figure 14 shows the rate for the average rutting strain per recovery elastic strain. From these figures, we can compare the performances of mixtures for the rutting. By comparing the rutting strains at temperature of $40^{\circ} \mathrm{C}$, we can conclude the $\mathrm{K} 4$ mixture has the greatest resistance of rutting. Then comes $\mathrm{K} 1, \mathrm{~K} 2$, and $\mathrm{KS}$ in order. In the comparison results at the temperature of $54^{\circ} \mathrm{C}, \mathrm{K} 4$ mixture has equally the greatest property and $\mathrm{KS}$ mixture has the worst property for rutting. The SBS-modified mixtures have the similar resistance for rutting. Therefore, the modified agent can affect the rutting at temperature of $40^{\circ} \mathrm{C}$. But modified agent types or contents cannot be affected at temperature of $54^{\circ} \mathrm{C}$. 


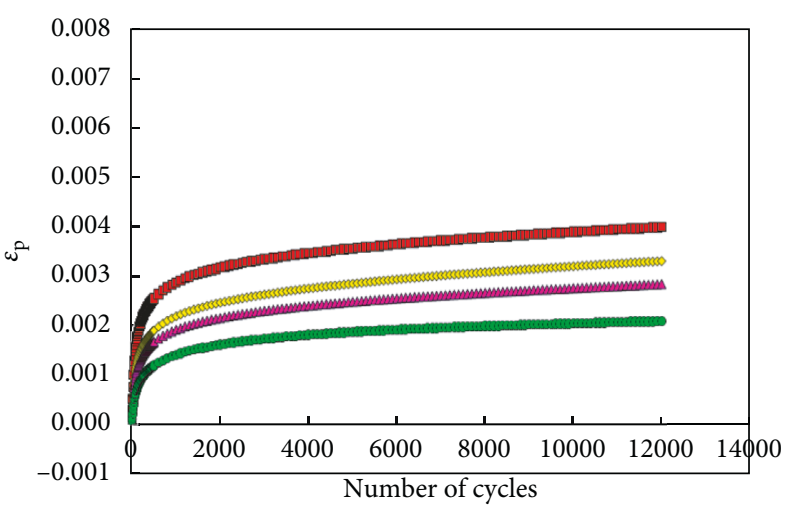

- Avg_KS_4 $0^{\circ} \mathrm{C} \quad \Delta$ Avg_K2_4 $40^{\circ} \mathrm{C}$

$\diamond$ Avg_K1_40 ${ }^{\circ} \mathrm{C}$

- Avg_K4_ $40^{\circ} \mathrm{C}$

(a)

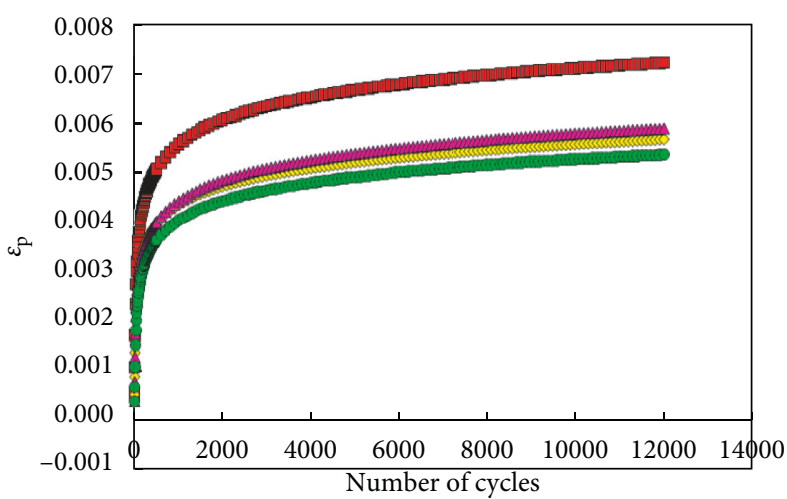

- Avg_KS_54 $5{ }^{\circ} \mathrm{C}$

$\diamond$ Avg_K1_5 $4^{\circ} \mathrm{C}$

$\Delta$ Avg_K2_5 $4^{\circ} \mathrm{C}$

- Avg_K4_54 ${ }^{\circ} \mathrm{C}$

(c)

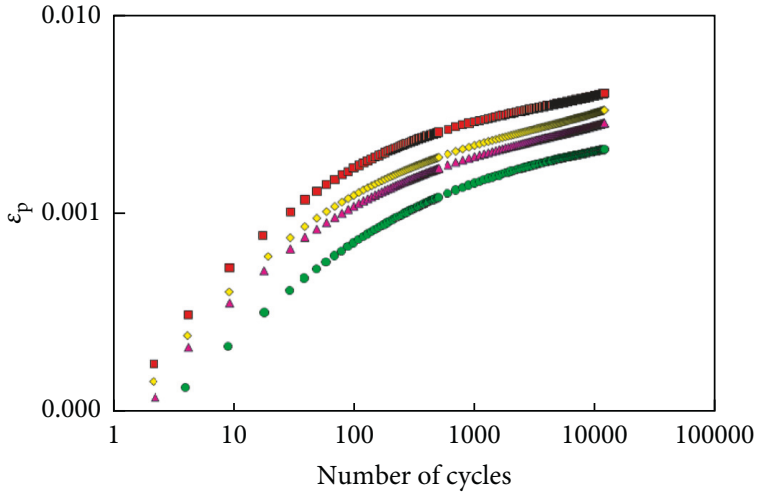

- Avg_KS_ $40^{\circ} \mathrm{C}$

$\Delta$ Avg_K2_40 ${ }^{\circ} \mathrm{C}$

• Avg_K1_40 $4{ }^{\circ} \mathrm{C}$

- Avg_K4_40 ${ }^{\circ} \mathrm{C}$

(b)

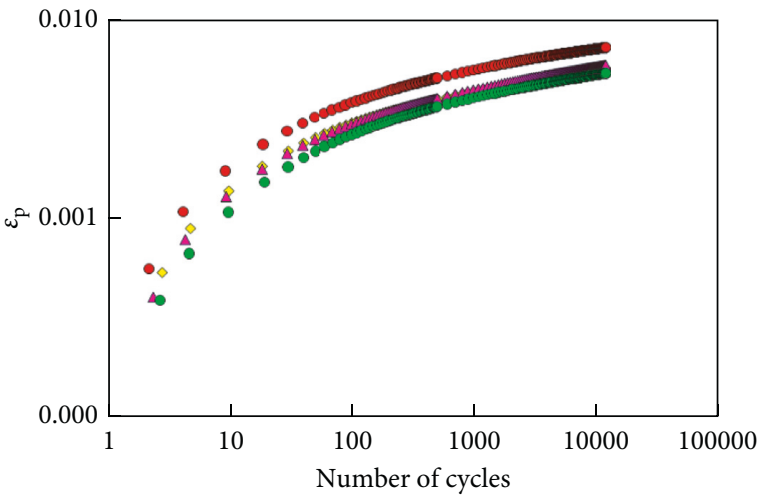

- Avg_KS_5 $54^{\circ} \mathrm{C}$

$\Delta$ Avg_K2_54 ${ }^{\circ} \mathrm{C}$

$\diamond$ Avg_K1_54 ${ }^{\circ} \mathrm{C}$

(d)

Figure 13: Comparison of permanent strain growth of the four mixtures: (a) at $40^{\circ} \mathrm{C}$ in arithmetic scale; (b) at $40^{\circ} \mathrm{C}$ in log-log scale; (c) at $54^{\circ} \mathrm{C}$ in arithmetic scale; (d) at $54^{\circ} \mathrm{C}$ in log-log scale.

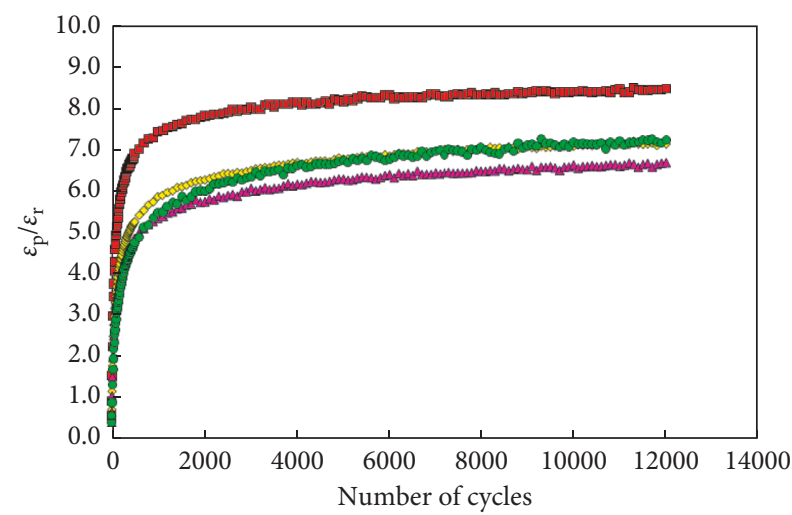

- Avg_KS_ $40^{\circ} \mathrm{C}$

$\diamond$ Avg_K1_40 $40^{\circ} \mathrm{C}$
$\Delta$ Avg_K2_40 $40^{\circ} \mathrm{C}$

- Avg_K4_40 $40^{\circ} \mathrm{C}$

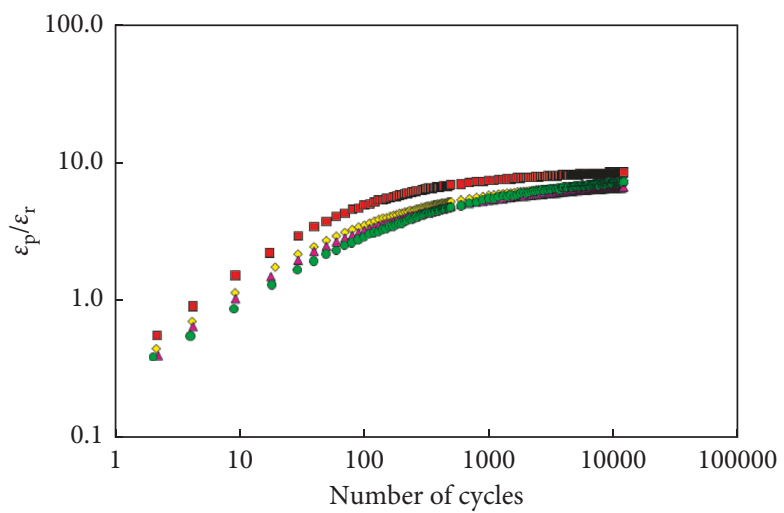

- Avg_KS_40 $40^{\circ} \mathrm{C}$

• Avg_K1_40 $40^{\circ} \mathrm{C}$
$\Delta$ Avg_K2_40 ${ }^{\circ} \mathrm{C}$

- Avg_K4_40 ${ }^{\circ} \mathrm{C}$

(a)

(b)

Figure 14: Continued. 


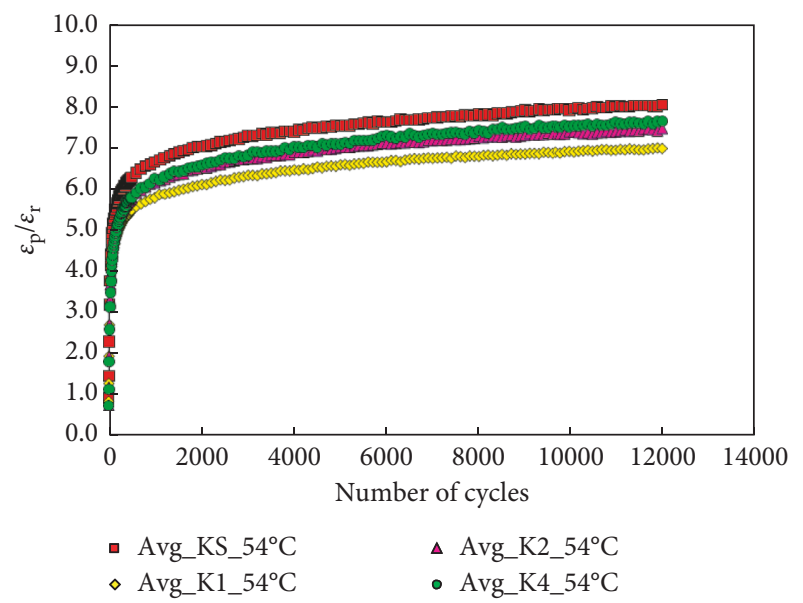

(c)

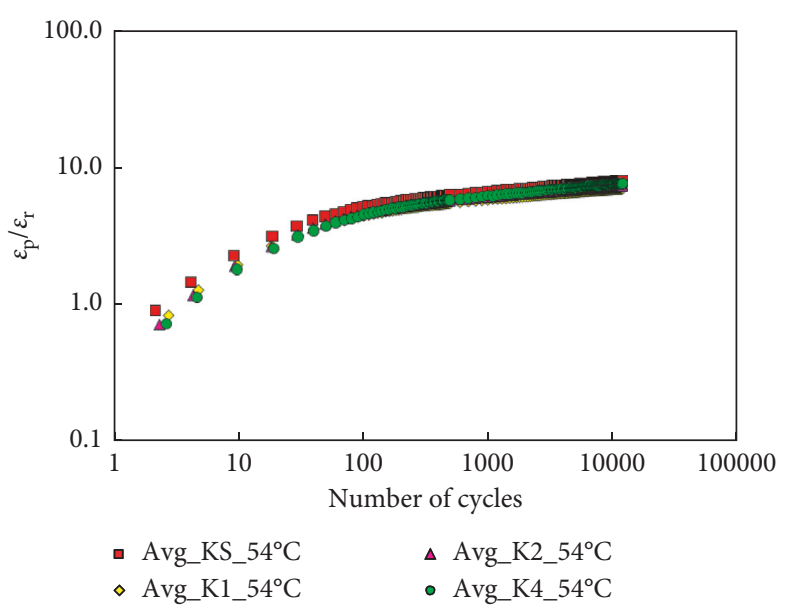

(d)

FIGURE 14: Comparison of permanent/resilient strain ratio growth of the four mixtures: (a) at $40^{\circ} \mathrm{C}$ in arithmetic scale; (b) at $40^{\circ} \mathrm{C}$ in log-log scale; (c) at $54^{\circ} \mathrm{C}$ in arithmetic scale; (d) at $54^{\circ} \mathrm{C}$ in log-log scale.

\section{Conclusions}

In this research, the performances for the rutting and fatigue failure were evaluated and compared using the SBS-modified mixtures developed by using the modified agents. The performance test for the fatigue failure was conducted by the VEPCD model, and the properties of mixtures were characterized. The performance for the fatigue failure at the real site's pavement was evaluated by using the VECD-FEP++. The performance of rutting for each mixture was evaluated by using the viscoplastic model from the tension test and triaxial compression test proposed by NCHRP 1-37 A MEPDG (AASHTO2004) and the rutting model.

With the results for evaluating the performance related to the fatigue failure, $\mathrm{K} 2$ mixture is the most suitable material to protect the fatigue cracking. K1 mixture is good to fatigue failure, but it has the low performance than K2 mixture. K4 mixture looks like it needs the attentive design. The elastic modulus of K4 mixture is higher than other SBS-modified mixtures, and the completely failed point $\left(C_{\mathrm{f}}\right)$ is higher than other mixtures. K4 mixture can be easy to break, even if it is stronger than other mixtures with these reasons. Therefore, SBS-modified mixtures are not suitable at the thin pavement and the environment having a lot of temperature differences per a day. While the properties of $\mathrm{K} 1$ and $\mathrm{K} 2$ mixtures are better than KS at any conditions, K4 mixture can be dissimilarly evaluated according to the analysis methods. It means that K4 mixture can have the lower property than KS mixture.

From the performance regarding the rutting, K4 mixture has the best performance at the average temperature for paving the pavement. Then comes $\mathrm{K} 2, \mathrm{~K} 1$, and $\mathrm{KS}$ mixtures in order. However, the performances for three types of SBSmodified mixtures are similar at the high-temperature condition, and the performance of KS mixture is lowest than that of other mixtures. Where, the real structure of pavement, environmental factors, and traffic factors should be considered to conduct the accurate analysis for the performance of rutting.
When considering the performances of rutting and fatigue failure, K2 mixture is the best SBS-modified material. The modified agent for K1 mixture has low performance than $\mathrm{K} 2$ mixture, and $\mathrm{K} 4$ mixture is good when the rutting is terribly occurred. But it needs serious caution to the failure.

\section{Data Availability}

The data used to support the findings of this study are included within the article.

\section{Conflicts of Interest}

The authors declare that they have no conflicts of interest.

\section{References}

[1] B. S. Underwood, Y. R. Kim, and M. N. Guddati, "Characterization and performance prediction of ALF mixtures using a viscoelastoplastic continuum damage model," Asphalt Paving Technology, vol. 75, pp. 577-636, 2006.

[2] J. S. Daniel, Development of a simplified fatigue test and analysis procedure using a viscoelastic, continuum damage model and its implementation to WesTrack mixtures, Ph.D. dissertation, North Carolina State University, Raleigh, NC, USA, 2001.

[3] G. Chehab, Characterization of asphalt concrete in tension using a viscoelastoplastic model, Ph.D. dissertation, North Carolina State University, Raleigh, NC, USA, 2002.

[4] American Association of State Highway and Transportation Officials, TP-62 Standard Method of Test for Determining Dynamic Modulus of Hot-Mix Asphalt Concrete Mixtures, American Association of State Highway and Transportation Officials, Washington, DC, USA, 2003.

[5] J. D. Ferry, Viscoelastic Properties of Polymers, John Wiley and Sons, Inc., New York, NY, USA, 1961.

[6] B. S. Underwood, Y. R. Kim, and M. N. Guddati, "Use of viscoelastic continuum damage model for asphalt concrete fatigue predictions," in Proceedings of 88th Annual 
Transportation Research Board Meeting, Washington, DC, USA, July 2008.

[7] N. H. Gibson, C. W. Schwartz, R. A. Schapery, and M. W. Witczak, "Viscoelastic, viscoplastic, and damage modeling of asphalt concrete in unconfined compression," Transportation Research Record: Journal of the Transportation Research Board, vol. 1860, pp. 3-15, 2003.

[8] T. Y. Yun and Y. R. Kim, "Viscoelastoplastic modeling of the behavior of hot mix asphalt in compression," KSCE Journal of Civil Engineering, vol. 17, no. 6, pp. 1323-1332, 2013.

[9] G Chehab, Y. R Kim, R. A Schapery, M. Witczack, and R. Bonaquist, "Time-temperature superposition principle for asphalt concrete mixtures with growing damage in tension state," Journal of the Association of Asphalt Paving Technologists, vol. 71, pp. 559-593, 2001.

[10] G. Chehab, Y. R. Kim, R. A. Schapery, M. W. Witczack, and R. Bonaquist, "Characterization of asphalt concrete in uniaxial tension using a viscoelastoplastic model," Journal of the Association of Asphalt Paving Technologists, vol. 72, pp. 315-355, 2003.

[11] S. Lee, Investigation of the effects of lime on the performance of HMA using advanced testing and modeling techniques, Ph.D. dissertation, North Carolina State University, Raleigh, NC, USA, 2007.

[12] D. Mensching, R. Rahbar-Rastegar, B. S. Underwood, and J. S. Daniel, "Identifying indicators for fatigue cracking in hotmix asphalt pavements using viscoelastic continuum damage principles," Journal of the Transportation Research Board, vol. 2576, pp. 28-39, 2016.

[13] W. A. Zeiada, B. S. Underwood, T. Pourshams, J. Stempihat, and K. E. Kaloush, "Comparison of conventional, polymer, and rubber asphalt mixtures using viscoelastic continuum damage model," Road Materials and Pavement Design, vol. 15, no. 3, pp. 588-605, 2014.

[14] B. S. Underwood, C. M. Baek, and Y. R. Kim, "Simplified viscoelastic continuum damage model as platform for asphalt concrete fatigue analysis," Journal of the Transportation Research Board, vol. 2296, no. 1, pp. 36-45, 2012. 


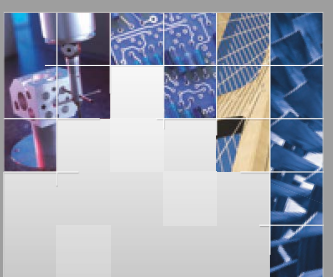

\section{Enfincering}
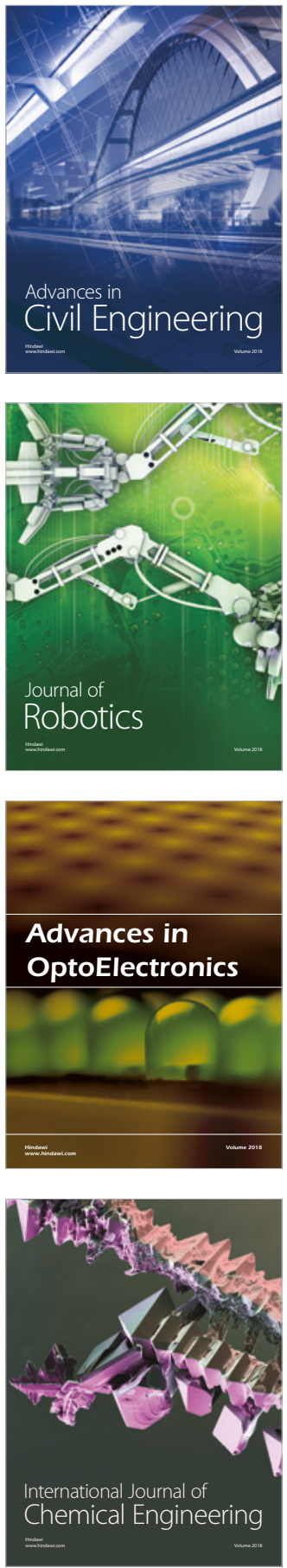

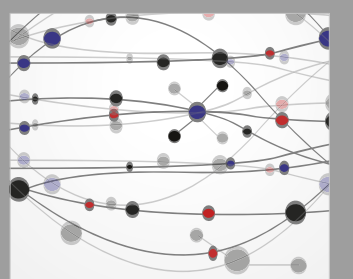

\section{Rotating \\ Machinery}

The Scientific World Journal

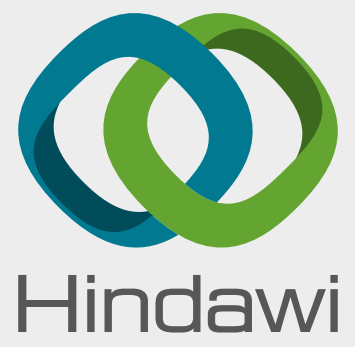

Submit your manuscripts at

www.hindawi.com
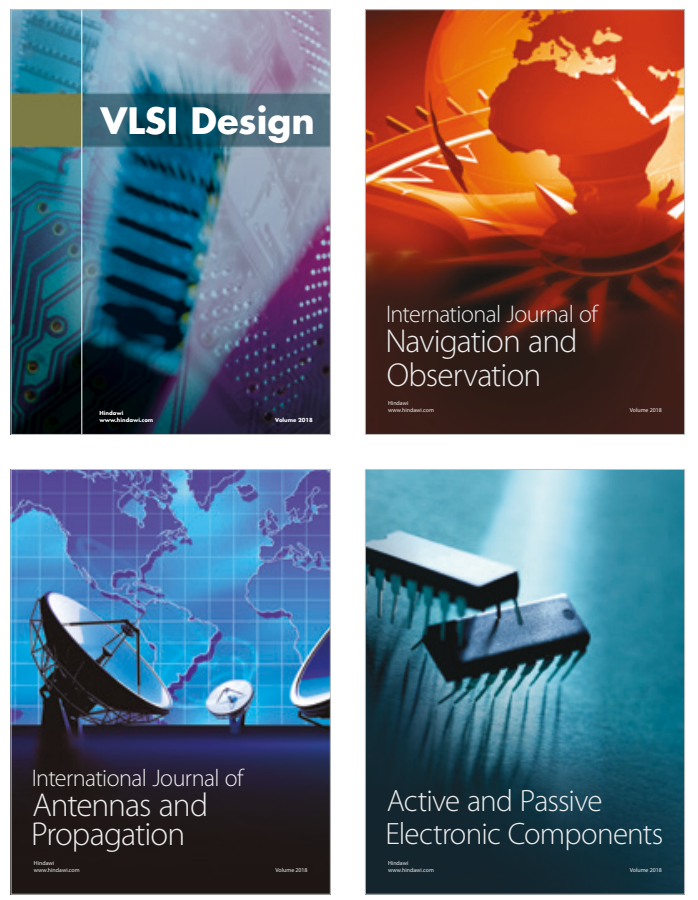
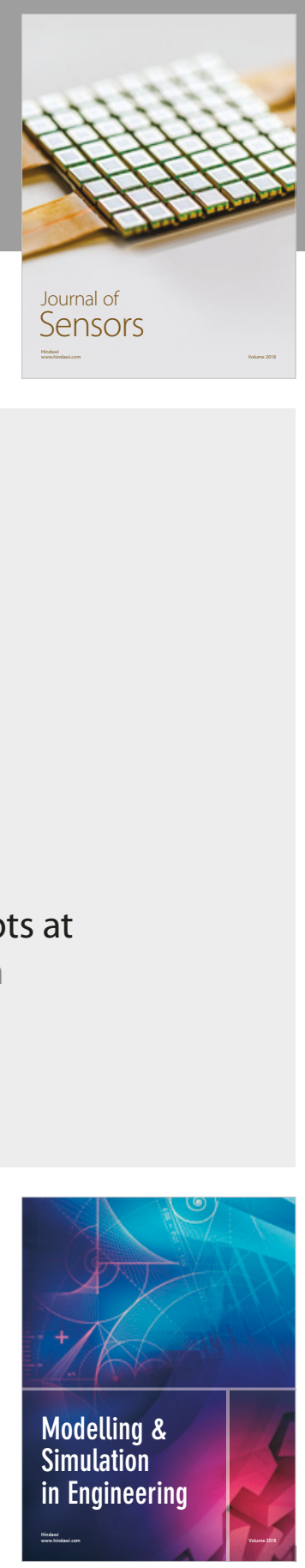

\section{Advances \\ Multimedia}
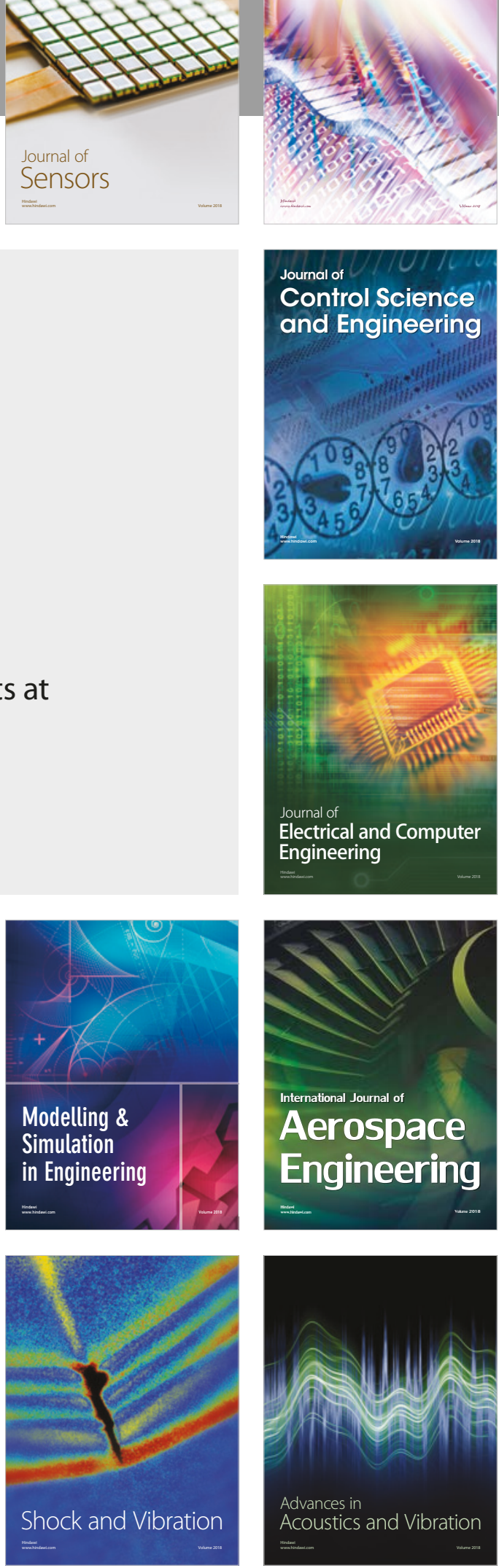